\title{
Anxious and non-anxious major depressive disorder in the World Health Organization World Mental Health Surveys
}

R. C. Kessler ${ }^{1 *}$, N. A. Sampson ${ }^{1}$, P. Berglund ${ }^{2}$, M. J. Gruber ${ }^{1}$, A. Al-Hamzawi ${ }^{3}$, L. Andrade ${ }^{4}$, B. Bunting ${ }^{5}$, K. Demyttenaere ${ }^{6}$, S. Florescu ${ }^{7}$, G. de Girolamo ${ }^{8}$, O. Gureje ${ }^{9}$, Y. $\mathrm{He}^{10}$, C. $\mathrm{Hu}^{11}$, Y. Huang ${ }^{12}$, E. Karam $^{13,14,15}$, V. Kovess-Masfety ${ }^{16}$, L Lee $^{17}$, D. Levinson ${ }^{18}$, M. E. Medina Mora ${ }^{19}$, J. Moskalewicz ${ }^{20}$, Y. Nakamura ${ }^{21}$, F. Navarro-Mateu ${ }^{22}$, M. A. Oakley Browne ${ }^{23}$, M. Piazza ${ }^{24}$, J. Posada-Villa ${ }^{25}$, T. Slade ${ }^{26}$, M. ten Have ${ }^{27}$, Y. Torres ${ }^{28}$, G. Vilagut ${ }^{29}$, M. Xavier ${ }^{30}$, Z. Zarkov $^{31}$, V. Shahly ${ }^{1}$ and M. A. Wilcox ${ }^{32}$

${ }^{1}$ Department of Health Care Policy, Harvard Medical School, Boston, MA, USA

${ }^{2}$ Institute for Social Research, University of Michigan, Ann Arbor, MI, USA

${ }^{3}$ College of Medicine, Al-Qadisiya University, Diwania governorate, Iraq

${ }^{4}$ Institute of Psychiatry, University of São Paulo Medical School, São Paulo, Brazil

${ }^{5}$ School of Psychology, Ulster University, Londonberry, Ireland

${ }^{6}$ Department of Psychiatry, University Hospital Gasthuisberg, Katholieke Universiteit Leuven, Leuven, Belgium

${ }^{7}$ National School of Public Health, Management and Professional Development, Bucharest, Romania

${ }^{8}$ Unit of Epidemiological and Evaluation Psychiatry, IRCCS St John of God Clinical Research Centre, Brescia, Italy

${ }^{9}$ Department of Psychiatry, Centre for Research and Training in Mental Health, Neurosciences, Drug and Alcohol Abuse, University of Ibadan, Ibadan, Nigeria

${ }^{10}$ Shanghai Mental Health Center, Shanghai Jiao Tong University, School of Medicine, Shanghai, People's Republic of China

${ }^{11}$ Shenzhen Institute of Mental Health \& Shenzhen Kanging Hospital, Guangdon Province, PRC

${ }^{12}$ Institute of Mental Health, Peking University, Beijing, China

${ }^{13}$ Department of Psychiatry and Clinical Psychology, Faculty of Medicine, Balamand University, Beirut, Lebanon

${ }^{14}$ Department of Psychiatry and Clinical Psychology, St George Hospital University Medical Center, Beirut, Lebanon

${ }^{15}$ Institute for Development Research Advocacy and Applied Care (IDRAAC), Beirut, Lebanon

${ }^{16}$ Ecole des Hautes Etudes en Santé Publique (EHESP), EA 4057 Paris Descartes University, Paris, France

${ }^{17}$ Department of Psychiatry, The Chinese University of Hong Kong, Shatin, Hong Kong SAR

${ }^{18}$ Ministry of Health Israel, Mental Health Services, Jerusalem, Israel

${ }^{19}$ Ramond e la Fuente Muñiz National Institute of Psychiatry, Mexico City, Mexico

${ }^{20}$ Institute of psychiatry and Neurology, Warsaw, Poland

${ }^{21}$ Department of Public Health, Jichi Medical University, Shimotsuke, Tochigi, Japan

${ }^{22}$ Unidad de Docencia, Investigación y Formación en Salud Mental (UDIF-SM), Servicio Murciano de Salud, IMIB-Arrixaca, CIBERESP-Nodo Murcia, Spain

${ }^{23}$ Department of Psychiatry, School of Medicine, University of Tasmania, Tasmania, Australia

${ }^{24}$ National Institute of Health, Lima, Peru

${ }^{25}$ Universidad Colegio Mayor de Cundinamarca, Bogota, Colombia

${ }^{26}$ National Drug and Alcohol Research Centre, University of New South Wales, Sydney, Australia

${ }^{27}$ Netherlands Institute of Mental Health and Addiction, Utrecht, The Netherlands

${ }^{28}$ Center for Excellence on Research in Mental Health, CES University, Medellin, Colombia

${ }^{29}$ Health Services Research Unit, IMIM (Institut Hospital del Mar d'Investigacions Mèdiques), Carrer del Doctor Aiguader, 88, Edifici PRBB, 08003, Barcelona, Spain

${ }^{30}$ Department of Mental Health - CEDOC and Faculdade Ciencias Medicas, Universidade Nova de Lisboa, Lisbon, Portugal

${ }^{31}$ Department Mental Health, NCPHA, Sofia, Bulgaria

${ }^{32}$ Janssen Pharmaceutical Research \& Development, Titusville, NJ, USA

Background. To examine cross-national patterns and correlates of lifetime and 12-month comorbid DSM-IV anxiety disorders among people with lifetime and 12-month DSM-IV major depressive disorder (MDD).

Method. Nationally or regionally representative epidemiological interviews were administered to 74045 adults in 27 surveys across 24 countries in the WHO World Mental Health (WMH) Surveys. DSM-IV MDD, a wide range of comorbid DSM-IV anxiety disorders, and a number of correlates were assessed with the WHO Composite International Diagnostic Interview (CIDI).

${ }^{*}$ Address for correspondence: R. C. Kessler, Department of Health Care Policy, Harvard Medical School, 180 Longwood Avenue, Boston, MA 02115, USA.

(Email: kessler@hcp.med.harvard.edu) 
Results. $45.7 \%$ of respondents with lifetime MDD (32.0-46.5\% inter-quartile range (IQR) across surveys) had one of more lifetime anxiety disorders. A slightly higher proportion of respondents with 12-month MDD had lifetime anxiety disorders $(51.7 \%, 37.8-54.0 \% \mathrm{IQR})$ and only slightly lower proportions of respondents with 12-month MDD had 12month anxiety disorders $(41.6 \%, 29.9-47.2 \%$ IQR). Two-thirds (68\%) of respondents with lifetime comorbid anxiety disorders and MDD reported an earlier age-of-onset (AOO) of their first anxiety disorder than their MDD, while 13.5\% reported an earlier AOO of MDD and the remaining 18.5\% reported the same AOO of both disorders. Women and previously married people had consistently elevated rates of lifetime and 12-month MDD as well as comorbid anxiety disorders. Consistently higher proportions of respondents with 12-month anxious than non-anxious MDD reported severe role impairment $\left(64.4 v .46 .0 \% ; \chi_{1}^{2}=187.0, p<0.001\right)$ and suicide ideation $\left(19.5 v .8 .9 \% ; \chi_{1}^{2}=71.6, p<0.001\right)$. Significantly more respondents with 12-month anxious than non-anxious MDD received treatment for their depression in the 12 months before interview, but this difference was more pronounced in high-income countries $\left(68.8 v .45 .4 \% ; \chi_{1}^{2}=\right.$ $108.8, p<0.001)$ than low/middle-income countries (30.3 v. 20.6\%; $\left.\chi_{1}^{2}=11.7, p<0.001\right)$.

Conclusions. Patterns and correlates of comorbid DSM-IV anxiety disorders among people with DSM-IV MDD are similar across WMH countries. The narrow IQR of the proportion of respondents with temporally prior AOO of anxiety disorders than comorbid MDD (69.6-74.7\%) is especially noteworthy. However, the fact that these proportions are not higher among respondents with 12-month than lifetime comorbidity means that temporal priority between lifetime anxiety disorders and MDD is not related to MDD persistence among people with anxious MDD. This, in turn, raises complex questions about the relative importance of temporally primary anxiety disorders as risk markers $v$. causal risk factors for subsequent MDD onset and persistence, including the possibility that anxiety disorders might primarily be risk markers for MDD onset and causal risk factors for MDD persistence.

Received 23 December 2014; Revised 20 January 2015; Accepted 21 January 2015; First published online 27 February 2015

Key words: Anxious depression, comorbidity, epidemiology.

\section{Introduction}

The Global Burden of Disease (GBD) 2010 Study ranked major depressive disorder (MDD) as the 2nd leading cause of years lived with disability in the world (exceeded only by low back pain) and the 1st4 th leading cause (out of nearly 300 considered) in each region of the world (Vos et al. 2012). These high estimates are due to MDD having both high prevalence (estimated by the GBD 2010 investigators to be the 19th most common disease in the world) and high severity (indicated by higher ranking of MDD as a cause of disability than prevalent disease). However, MDD severity is highly variable (Birnbaum et al. 2010; Li et al. 2014). Indeed, severity is the most consistent discriminating characteristic in empirical studies of MDD symptom subtypes (van Loo et al. 2012).

One of the strongest predictors of MDD severity is comorbid anxiety disorder (Mineka \& VrshekSchallhorn, 2008; Wu \& Fang, 2014). Epidemiological studies show consistently that MDD is highly comorbid with numerous anxiety disorders (Andrade et al. 2003; Kessler et al. 2011b; Lamers et al. 2011) and more severe and persistent when accompanied by comorbid anxiety disorders (Ormel et al. 1994; Roy-Byrne et al. 2000; McLaughlin et al. 2006; Fichter et al. 2010). People with anxious MDD are also significantly more likely to seek treatment (Kessler et al. 2001; Jacobi et al. 2004) but significantly less likely to respond to treatment (Jakubovski \& Bloch, 2014;
Saveanu et al. 2014) than those with non-anxious MDD. Comorbid anxiety disorders have been found consistently to have earlier age-of-onset (AOO) than MDD both in cross-sectional surveys that assess AOO retrospectively (Kessler, 1995; Kessler et al. 2011a) and prospective studies that examine unfolding of comorbidity over time (Murphy et al. 1986; Bittner et al. 2004; Copeland et al. 2009; Klein et al. 2013).

Two noteworthy limitations of existing research on comorbid anxiety in MDD are that a narrow definition of comorbid anxiety is often used that either focuses on current (but not lifetime) comorbidity or examines only one anxiety disorder (typically generalised anxiety disorder or panic disorder) and that these studies are typically, although not always (Lin et al. 2014), carried out in high-income Western countries. We address both limitations here by presenting cross-national epidemiological data on comorbidities of DSM-IV anxiety disorders and MDD using a composite measure that includes a wide range of anxiety disorders in a coordinated series of 27 community epidemiological surveys carried out in 24 countries throughout the world. We estimate the proportions of survey respondents with lifetime and 12-month DSM-IV MDD who also met criteria for one or more lifetime and 12-month DSM-IV anxiety disorders. We examine cross-national consistencies in AOO priorities between comorbid anxiety disorders and MDD, whether anxious MDD is more severe and persistent than non-anxious MDD, and 
whether people with anxious MDD are more likely than those with non-anxious MDD to obtain professional treatment for MDD. We also examine crossnational consistency in basic socio-demographic correlates of anxious and non-anxious MDD.

\section{Methods}

Sample

Data come from the WHO World Mental Health (WMH) Surveys, a series of community epidemiological surveys administered in ten countries classified by the World Bank (World Bank, 2009) as low or middle-income (Brazil, Bulgaria, Colombia, Iraq, Lebanon, Mexico, Nigeria, Peru, Peoples Republic of China (PRC) and Romania) and 14 high income (Australia, Belgium, France, Germany, Israel, Italy, Japan, Netherlands, New Zealand, Northern Ireland, Poland, Portugal, Spain and the USA). The majority of surveys (five in low/middle-income countries, 13 in high-income countries) were based on nationally representative household samples. Two were representative of all urban areas in their countries (Colombia, Mexico). Two were representative of selected regions in their countries (Japan, Nigeria). And a final five were representative of selected Metropolitan Areas in their countries (Sao Paulo in Brazil; Medellin in Colombia; Murcia in Spain; BeijingShanghai and Shenzhen in PRC).

Standardised interviewer training and quality control procedures were used in each survey (Pennell et al. 2008). Informed consent was obtained before administering interviews. The institutional review boards of the organisations coordinating the surveys approved and monitored compliance with procedures for informed consent and protecting human subjects. Interviews were administered face-to-face by trained lay interviewers in respondents' homes. A total of 138602 adults (age 18+) completed interviews. The weighted (by sample size) average response rate was $68.7 \%$. To reduce respondent burden, the interview was divided into two parts. Part I, which assessed core mental disorders, was administered to all respondents. Part II, which assessed additional disorders and correlates, was administered to all Part I respondents who met criteria for any Part I disorder plus a probability subsample of other Part I respondents. Part II interviews ( $n=74045)$, the focus of the current report, were weighted by the inverse of their probabilities of selection into Part II and additionally weighted to adjust samples to match population distributions on the cross-classification of key socio-demographic and geographic variables. Further details about WMH sampling and weighting are available elsewhere (Heeringa et al. 2008).

\section{Measures}

Mental disorders

Mental disorders were assessed with the WHO Composite International Diagnostic Interview (CIDI) Version 3.0, (Kessler \& Üstün, 2004), a fully structured lay-administered interview generating lifetime and 12-month prevalence estimates of 20 mood (major depressive, dysthymic, bipolar I-II and sub-threshold bipolar), anxiety (generalised anxiety, panic, agoraphobia, specific phobia, social phobia, post-traumatic stress, and separation anxiety), behaviour (attention-deficit/ hyperactivity, oppositional-defiant, conduct, intermittent explosive) and substance (alcohol and drug abuse, alcohol and drug dependence with abuse) disorders. The WMH interview translation, back-translation and harmonisation protocol required culturally competent bilingual clinicians to review, modify, and approve key phrases describing symptoms (Harkness et al. 2008). However, no attempt was made to go beyond DSM-IV criteria to assess depression-equivalents that might be unique to the specific countries. The latter expansion might have led to a change in results, although previous research has shown that the latent structure of major depression is quite consistent across countries (Simon et al. 2002; Bernert et al. 2009; Schrier et al. 2010). Blinded clinical reappraisal interviews with the Structured Clinical Interview for DSM-IV (SCID; First et al. 2002) were carried out in four $\mathrm{WMH}$ countries. Good concordance was found with diagnoses based on the CIDI (Haro et al. 2006). AOO was assessed using a special probing sequence shown experimentally to yield more plausible distributions than conventional AOO questions (Knäuper et al. 1999).

MDD was defined as meeting lifetime DSM-IV/CIDI criteria for major depressive episode (MDE) and not meeting lifetime DSM-IV/CIDI criteria for broadly defined bipolar disorder (bipolar I-II or sub-threshold). As detailed elsewhere (Merikangas et al. 2011), our definition of sub-threshold bipolar disorder includes both hypomania without history of MDE and sub-threshold hypomania with history of MDE. Anxious MDD is defined as MDD in conjunction with any of the anxiety disorders assessed in the surveys. Comorbid anxiety is considered temporally primary if at least one lifetime anxiety disorder had an AOO earlier than that of MDD. MDD is considered temporally primary if MDD AOO is earlier than that of all lifetime comorbid anxiety disorders. A third category consists of respondents who reported that MDD AOO was the same as anxiety disorder AOO.

\section{Impairment in role functioning}

Severe role impairment in the 12 months before interview was assessed with a modified version of the 
Sheehan Disability Scales (SDS; Leon et al. 1997) that asked respondents with 12-month MDD to think of the 1 month in the year when their depression was most severe and rate how much their depression interfered with their functioning in each of four role domains (home management, ability to work, social life and close relationships) during that month using a $0-10$ response scale with labels of None (0), Mild (1-3), Moderate (4-6), Severe (7-9) and Very Severe (10) interference. Severe role impairment was defined as having any SDS score of 7-10. The SDS has excellent internal consistency reliability (Leon et al. 1997) and good concordance with objective measures of role functioning (Ormel et al. 2008). Suicide ideation was assessed with a single question that asked respondents whether there was ever a time in the 12 months before interview when they 'seriously thought about committing suicide'.

\section{Socio-demographics}

We examined associations of MDD with respondent age (18-34, 35-49, 50-64, 65+), gender, current marital status (married, never married, previously married (combining separated, divorced and widowed)), current income (low, low-average, high-average and high based on country-specific quartiles of gross household income per family member) and education (none, some primary, completed primary, some secondary, completed secondary, some college or other post-secondary and completed college).

\section{Treatment}

Respondents with lifetime MDD were asked if they ever obtained professional treatment for their depression and, if so, if they did so in the past 12 months. Those with 12-month treatment were asked if they saw a mental health specialty treatment provider (psychiatrist, psychologist, other mental health professional in any setting, social worker or counsellor in a mental health specialty treatment setting, used a mental health hotline) general medical treatment provider (primary care doctor, other general medical doctor, any other health care profession seen in a general medical setting) or nonmedical treatment provider (religious or spiritual advisor, social worker or counsellor, any other type of healer) for a mental health problem. A more detailed description of WMH 12-month treatment measures is presented elsewhere (Wang et al. 2007).

\section{Statistical analyses}

Cross-tabulations were used to estimate lifetime and 12-month DSM-IV/CIDI MDD prevalence, the proportions of lifetime and 12-month cases with comorbid DSM-IV anxiety disorders, the proportions of lifetime comorbid cases with anxiety disorder or MDD temporally primary AOO, 12-month prevalence of severe role impairment and suicide ideation related to comorbid anxiety disorders among respondents with 12-month MDD, and 12-month MDD treatment as a function of comorbid anxiety disorders among respondents with 12-month MDD. Person-level logistic regression was used to examine multivariate associations of socio-demographic variables with lifetime and 12-month MDD in the total sample, lifetime anxious MDD among respondents with lifetime MDD, and 12-month anxious MDD among respondents with 12-month MDD. Time-varying socio-demographics (i.e., marital status, income and education) were defined as of the time of interview (rather than at time of disorder onset). Standard errors were estimated using the Taylor series linearisation method (Wolter, 1985) implemented in the SUDAAN software system (Research Triangle Institute, 2002) to adjust weighting and clustering. Multivariate significance of predictor sets was evaluated using Wald $\chi^{2}$ tests based on design-corrected coefficient variance-covariance matrices. Statistical significance was evaluated using two-sided 0.05-level tests.

\section{Results}

\section{Prevalence}

Lifetime prevalence of DSM-IV/CIDI MDD averaged $11.2 \%$ across surveys, $8.1 \%$ in low/middle-income countries, and $13.0 \%$ in high-income countries. (Table 1 ) The inter-quartile range (IQR; 25th-75th percentiles) of lifetime prevalence estimates was $6.8-15.3 \%$. The $45.7 \%$ of respondents with lifetime MDD $(42.4 \%$ in low/ middle-income countries, $46.9 \%$ in high-income countries, $32.0-46.5 \% \mathrm{IQR}$ ) also had one of more lifetime DSM-IV/CIDI anxiety disorders. A comparison of the ratios of (75th percentile - 25th percentile)/mean shows that lifetime prevalence varied much more across surveys than did the proportion of lifetime cases with lifetime comorbid anxiety disorders (0.75 v. 0.32).

Twelve-month MDD prevalence averaged $4.7 \%$ across surveys $(4.0 \%$ in low/middle-income countries, $5.1 \%$ in high-income countries, 3.0-5.6 IQR), while $51.7 \%$ of respondents with $12-$ month MDD $(48.0 \%$ in low/middle-income countries, $53.3 \%$ in high-income countries, $37.8-54.0 \%$ IQR) also had one or more lifetime DSM-IV/CIDI anxiety disorders. Only slightly lower proportions of respondents with 12-month MDD had 12-month comorbid anxiety disorders (41.6\% in the total sample, $38.8 \%$ in low/middleincome countries, $42.9 \%$ in high-income countries, $29.9-47.2 \%$ IQR). As with lifetime prevalence, a comparison of the ratios of (75th percentile - 25th 
Table 1. Lifetime and 12-month prevalence of DSM-IVICIDI MDD along with the proportions of respondents with lifetime and 12-month MDD who have comorbid DSM-IVICIDI anxiety disorders ${ }^{a}$ in the WHO WMH Surveys

\begin{tabular}{|c|c|c|c|c|c|c|c|c|c|c|c|}
\hline & \multicolumn{4}{|c|}{ Lifetime MDD } & \multicolumn{7}{|c|}{ 12-Month MDD } \\
\hline & \multicolumn{2}{|c|}{$\begin{array}{l}\text { Lifetime } \\
\text { MDD }\end{array}$} & \multicolumn{2}{|c|}{$\begin{array}{l}\text { Lifetime } \\
\text { anxiety/ } \\
\text { Lifetime } \\
\text { MDD }\end{array}$} & \multicolumn{2}{|c|}{$\begin{array}{l}\text { 12-month } \\
\text { MDD }\end{array}$} & \multicolumn{2}{|c|}{$\begin{array}{l}\text { Lifetime } \\
\text { anxiety/ } \\
\text { 12-month } \\
\text { MDD }\end{array}$} & \multicolumn{2}{|c|}{$\begin{array}{l}\text { 12-month } \\
\text { anxiety/ } \\
\text { 12-month } \\
\text { MDD }\end{array}$} & \multirow[b]{2}{*}{ (n) } \\
\hline & $\%$ & (S.E.) & $\%$ & (S.E.) & $\%$ & (S.E.) & $\%$ & (S.E.) & $\%$ & (S.E.) & \\
\hline \multicolumn{12}{|l|}{ I. Low/Middle Income } \\
\hline Brazil - São Paulo & 18.0 & $(0.8)$ & 50.0 & $(2.2)$ & 10.1 & $(0.6)$ & 51.2 & $(2.9)$ & 39.9 & $(2.8)$ & (2942) \\
\hline Bulgaria & 6.7 & $(0.5)$ & 32.5 & (3.3) & 3.0 & $(0.3)$ & 37.8 & $(5.0)$ & 36.7 & $(4.9)$ & (2233) \\
\hline Colombia & 11.8 & $(0.7)$ & 50.4 & $(3.0)$ & 5.3 & $(0.5)$ & 63.8 & $(4.1)$ & 50.7 & $(4.4)$ & $(2381)$ \\
\hline Columbia - Medellin & 9.9 & $(0.7)$ & 51.4 & (3.6) & 3.8 & $(0.4)$ & 54.0 & $(5.2)$ & 47.3 & (5.1) & (1673) \\
\hline Iraq & 7.2 & $(0.6)$ & 46.1 & $(4.2)$ & 3.9 & $(0.4)$ & 50.7 & $(5.8)$ & 42.1 & $(5.7)$ & $(4332)$ \\
\hline Lebanon & 10.3 & $(0.8)$ & 44.7 & (3.6) & 4.9 & $(0.5)$ & 43.6 & $(5.3)$ & 35.1 & $(5.0)$ & $(1031)$ \\
\hline Mexico & 7.6 & $(0.5)$ & 46.5 & $(2.9)$ & 3.7 & $(0.3)$ & 59.4 & (3.9) & 46.0 & (4.1) & (2362) \\
\hline Nigeria & 3.2 & $(0.3)$ & 19.1 & (3.5) & 1.1 & $(0.2)$ & 20.3 & (5.9) & 18.7 & $(5.8)$ & (2143) \\
\hline Peru & 6.4 & $(0.4)$ & 35.9 & (3.3) & 2.7 & $(0.3)$ & 49.5 & $(5.4)$ & 37.2 & (5.1) & (1801) \\
\hline $\mathrm{PRC}^{\mathrm{b}}$ - Beijing/Shanghai & 3.8 & $(0.4)$ & 25.3 & $(6.0)$ & 2.0 & $(0.3)$ & 36.8 & (9.5) & 33.6 & $(9.7)$ & (1628) \\
\hline $\mathrm{PRC}^{\mathrm{b}}$ - Shenzhen & 6.8 & $(0.6)$ & 18.7 & (3.4) & 3.6 & $(0.4)$ & 22.0 & (3.8) & 16.2 & (3.4) & (2475) \\
\hline Romania & 2.9 & $(0.4)$ & 27.0 & $(5.7)$ & 1.5 & $(0.3)$ & 31.5 & $(8.8)$ & 25.9 & $(8.4)$ & (2357) \\
\hline Total & 8.1 & $(0.2)$ & 42.4 & $(1.1)$ & 4.0 & $(0.1)$ & 48.0 & (1.6) & 38.8 & (1.5) & (27 358) \\
\hline \multicolumn{12}{|l|}{ II. High Income } \\
\hline Australia & 12.8 & $(0.5)$ & 51.4 & $(2.1)$ & 4.8 & $(0.3)$ & 59.0 & (3.5) & 49.0 & (3.4) & $(8841)$ \\
\hline Belgium & 14.1 & (1.1) & 29.8 & (3.3) & 5.2 & $(0.7)$ & 37.7 & (6.3) & 29.9 & (5.6) & (1043) \\
\hline France & 20.4 & $(1.2)$ & 41.6 & (2.6) & 5.6 & $(0.6)$ & 51.0 & (5.3) & 41.8 & (5.3) & (1436) \\
\hline Germany & 10.3 & $(0.7)$ & 45.0 & (3.1) & 3.1 & $(0.4)$ & 57.9 & (5.6) & 48.7 & (5.7) & (1323) \\
\hline Israel & 9.8 & $(0.4)$ & 21.9 & $(2.0)$ & 5.9 & $(0.4)$ & 23.7 & $(2.7)$ & 18.1 & $(2.4)$ & $(4859)$ \\
\hline Italy & 9.7 & $(0.5)$ & 39.3 & (2.6) & 2.9 & $(0.3)$ & 46.2 & (5.1) & 41.3 & (5.0) & (1779) \\
\hline Japan & 6.8 & $(0.5)$ & 27.6 & (3.5) & 2.4 & $(0.3)$ & 42.2 & (6.7) & 29.1 & (5.9) & (1682) \\
\hline Netherlands & 18.0 & (1.3) & 40.6 & (3.3) & 4.9 & $(0.7)$ & 49.3 & (6.6) & 32.5 & (5.9) & (1094) \\
\hline New Zealand & 15.8 & $(0.5)$ & 52.4 & (1.4) & 5.7 & $(0.3)$ & 60.3 & $(2.4)$ & 49.5 & $(2.4)$ & (7312) \\
\hline Northern Ireland & 17.7 & $(1.0)$ & 56.8 & $(2.8)$ & 8.8 & $(0.7)$ & 61.4 & $(4.4)$ & 47.2 & (4.3) & (1986) \\
\hline Poland & 3.8 & $(0.3)$ & 32.2 & (3.6) & 1.6 & $(0.2)$ & 36.7 & (5.1) & 27.8 & (4.6) & $(4000)$ \\
\hline Portugal & 17.4 & $(0.8)$ & 45.3 & $(2.1)$ & 7.0 & $(0.5)$ & 49.8 & (3.3) & 42.5 & (3.3) & (2060) \\
\hline Spain & 10.4 & $(0.6)$ & 34.9 & $(2.6)$ & 3.8 & $(0.3)$ & 48.4 & (4.5) & 40.0 & (4.3) & (2121) \\
\hline Spain - Murcia & 15.3 & $(1.0)$ & 32.0 & $(3.0)$ & 6.9 & $(0.7)$ & 36.7 & $(4.8)$ & 23.2 & (3.8) & (1459) \\
\hline US & 16.6 & $(0.5)$ & 62.6 & (1.4) & 6.7 & $(0.3)$ & 71.9 & (1.9) & 58.5 & (2.2) & (5692) \\
\hline Total & 13.0 & $(0.2)$ & 46.9 & $(0.7)$ & 5.1 & $(0.1)$ & 53.3 & (1.1) & 42.9 & (1.1) & $(46687)$ \\
\hline III. Total & 11.2 & $(0.1)$ & 45.7 & $(0.6)$ & 4.7 & $(0.1)$ & 51.7 & $(0.9)$ & 41.6 & $(0.9)$ & (74 045) \\
\hline
\end{tabular}

${ }^{a}$ Anxiety disorders include generalised anxiety disorder, panic disorder with or without agoraphobia, agoraphobia without a history of panic disorder, specific phobia, social phobia, separation anxiety and post-traumatic stress disorder.

beople's Republic of China.

percentile)/mean shows that 12-month prevalence varied more across surveys than did the proportion of 12-month cases with 12-month comorbid anxiety disorders (0.55 v. 0.42).

\section{AOO priorities}

Two-thirds (68.0\%) of respondents with lifetime anxious MDD reported first onset of anxiety disorders at earlier ages than MDD (71.5\% in low/middle-income countries, $66.9 \%$ in high-income countries, $69.6-74.7 \%$ IQR), (Table 2) while $13.5 \%$ reported earlier AOO of MDD than anxiety disorder $(11.3 \%$ in low/middle-income countries, $14.2 \%$ in high-income countries, $10.2-15.6 \%$ $\mathrm{IQR})$ and the remaining $18.5 \%(17.2 \%$ in low/ middle-income countries, $18.9 \%$ in high-income countries, $10.6-23.7 \%$ IQR) reported the same AOO of anxiety disorders and MDD. The dominant temporal 
Table 2. Temporal priority in AOO distributions of lifetime DSM-IVICIDI MDD and anxiety disorders ${ }^{a}$ among respondents with lifetime and 12-month comorbid MDD and anxiety disorders in the WHO WMH Surveys

\begin{tabular}{|c|c|c|c|c|c|c|c|c|c|c|}
\hline & \multicolumn{5}{|c|}{ Among lifetime comorbid cases ${ }^{b}$} & \multicolumn{5}{|c|}{ Among 12-Month comorbid cases ${ }^{b}$} \\
\hline & \multicolumn{2}{|c|}{ Anxiety first } & \multicolumn{2}{|c|}{ MDD first } & \multirow[b]{2}{*}{$(n)$} & \multicolumn{2}{|c|}{ Anxiety first } & \multicolumn{2}{|c|}{ MDD first } & \multirow[b]{2}{*}{ (n) } \\
\hline & $\%$ & (s.E.) & $\%$ & (s.е.) & & $\%$ & (S.E.) & $\%$ & (S.E.) & \\
\hline \multicolumn{11}{|l|}{ I. Low/Middle Income } \\
\hline Brazil - São Paulo & $76.6^{*}$ & (2.6) & 12.8 & $(2.0)$ & $(439)$ & $75.6^{*}$ & (3.4) & 15.7 & (3.0) & (205) \\
\hline Bulgaria & $62.8^{*}$ & (5.6) & 11.0 & (3.1) & (145) & $62.0^{*}$ & (7.6) & 13.1 & $(4.2)$ & (54) \\
\hline Colombia & $78.3^{*}$ & $(3.0)$ & 8.2 & $(1.8)$ & $(285)$ & $84.4^{*}$ & (3.3) & 9.3 & $(2.7)$ & (110) \\
\hline Columbia - Medellin & $79.2^{*}$ & $(3.4)$ & 10.1 & (2.5) & $(186)$ & $87.4^{*}$ & $(4.1)$ & 6.9 & $(3.0)$ & (73) \\
\hline Iraq & $44.4^{*}$ & (6.3) & 12.2 & (3.5) & (167) & $47.6^{*}$ & $(8.2)$ & 11.0 & (5.1) & (81) \\
\hline Lebanon & $68.1^{*}$ & $(4.8)$ & 17.2 & $(4.1)$ & (128) & $68.1^{*}$ & $(4.8)$ & 18.8 & (6.4) & (49) \\
\hline Mexico & $78.7^{*}$ & (3.6) & 13.4 & (3.1) & (212) & $77.8^{*}$ & $(4.1)$ & 15.8 & (3.7) & (101) \\
\hline Nigeria & $88.9^{*}$ & $(4.7)$ & 5.2 & (3.3) & $(36)$ & $86.1^{*}$ & (9.1) & 7.8 & (7.9) & (12) \\
\hline Peru & $66.5^{*}$ & (5.3) & 15.6 & $(4.0)$ & (85) & $69.3^{*}$ & (6.9) & 17.3 & (5.6) & (37) \\
\hline $\mathrm{PRC}^{\mathrm{C}}-$ Beijing/Shanghai & $74.4^{*}$ & (9.5) & 5.1 & (3.6) & $(40)$ & $70.0^{*}$ & $(13.1)$ & 5.1 & (4.5) & (21) \\
\hline PRC $^{\mathrm{C}}$ - Shenzhen & $87.5^{*}$ & $(5.20$ & 4.0 & $(2.2)$ & (70) & $84.7^{*}$ & $(7.1)$ & 2.9 & (2.2) & (37) \\
\hline Romania & $89.9^{*}$ & $(5.70$ & 3.9 & (2.5) & (25) & $97.2^{*}$ & (3.0) & 2.8 & (3.0) & (11) \\
\hline Total & $71.5^{*}$ & (1.5) & 11.3 & $(1.0)$ & $(1782)$ & $72.9^{*}$ & $(2.0)$ & 12.4 & (1.4) & (791) \\
\hline \multicolumn{11}{|l|}{ II. High Income } \\
\hline Australia & $62.8^{*}$ & (2.6) & 13.5 & $(1.8)$ & $(623)$ & $62.0^{*}$ & $(4.0)$ & 16.2 & $(2.8)$ & (229) \\
\hline Belgium & $64.4^{*}$ & $(6.8)$ & 14.2 & $(5.4)$ & $(106)$ & $65.9^{*}$ & $(10.1)$ & 21.5 & $(10.0)$ & (39) \\
\hline France & $70.2^{*}$ & (3.8) & 15.6 & (2.9) & $(261)$ & $64.1^{*}$ & $(7.3)$ & 18.0 & $(5.4)$ & (68) \\
\hline Germany & $69.6^{*}$ & $(4.9)$ & 17.1 & $(4.8)$ & $(164)$ & $72.8^{*}$ & $(8.0)$ & 19.9 & (8.0) & (55) \\
\hline Israel & 30.0 & (4.8) & 33.3 & (4.7) & (104) & 31.0 & (6.1) & 32.5 & (5.9) & (48) \\
\hline Italy & $57.9^{*}$ & (4.3) & 12.8 & (3.0) & (172) & $56.9^{*}$ & (7.4) & 13.8 & $(5.8)$ & (51) \\
\hline Japan & $55.8^{*}$ & (7.4) & 5.4 & (3.2) & $(64)$ & $59.1^{*}$ & $(10.4)$ & 7.2 & (5.3) & (25) \\
\hline Netherlands & $58.1^{*}$ & $(4.8)$ & 18.7 & $(4.4)$ & $(186)$ & 52.8 & $(8.5)$ & 31.4 & (8.5) & (40) \\
\hline New Zealand & $70.2^{*}$ & (1.8) & 10.2 & (1.3) & $(1125)$ & $71.1^{*}$ & (2.8) & 12.8 & (2.3) & (370) \\
\hline Northern Ireland & $74.7^{*}$ & (3.1) & 17.1 & $(2.7)$ & $(282)$ & $77.2^{*}$ & $(4.0)$ & 13.8 & (3.2) & (110) \\
\hline Poland & $73.3^{*}$ & (5.7) & 17.5 & $(4.9)$ & $(89)$ & $71.1^{*}$ & $(8.2)$ & 21.9 & (7.9) & (36) \\
\hline Portugal & $69.5^{*}$ & $(2.8)$ & 17.3 & (2.3) & (338) & $72.8^{*}$ & (4.1) & 17.9 & (3.7) & (126) \\
\hline Spain & $56.8^{*}$ & (4.4) & 11.2 & (2.5) & (217) & $50.7^{*}$ & (6.1) & 14.5 & $(4.2)$ & (87) \\
\hline Spain - Murcia & $49.7^{*}$ & (5.5) & 22.3 & $(4.8)$ & (131) & 44.7 & (7.8) & 31.5 & (7.8) & (45) \\
\hline US & $75.6^{*}$ & (1.6) & 12.5 & (1.3) & (957) & $77.5^{*}$ & $(2.2)$ & 13.2 & (1.8) & (375) \\
\hline Total & $66.9^{*}$ & $(0.9)$ & 14.2 & $(0.7)$ & $(4818)$ & $66.7^{*}$ & (1.3) & 16.5 & (1.1) & (1704) \\
\hline III. Total & $68.0^{*}$ & $(0.8)$ & 13.5 & (0.6) & $(6600)$ & 68.5 & (1.1) & 15.3 & $(0.9)$ & (2495) \\
\hline
\end{tabular}

*Significant difference between the proportion of cases with anxiety temporally primary $v$. MDD temporally primary at the 0.05 level, two-sided test.

${ }^{a}$ Anxiety disorders include generalised anxiety disorder, panic disorder with or without agoraphobia, agoraphobia without a history of panic disorder, specific phobia, social phobia, separation anxiety and post-traumatic stress disorder.

${ }^{b}$ Percentages with MDD first and anxiety first sum to less than 100\% because some respondents reported that their MDD and anxiety disorders started at the same age. In cases where respondents had multiple anxiety disorders, earliest AOO was used. 'People's Republic of China.

priority of anxiety disorders before MDD occurred in all surveys other than in Israel, where the proportions with temporally primary anxiety $(30.0 \%)$ and MDD (33.3\%) were virtually the same $\left(\chi_{1}^{2}=0.2, p=0.62\right)$.

Comparable proportions of respondents reporting temporally primary anxiety disorders were found for 12 -month comorbid cases $(68.5 \%$ in the total sample,
$72.9 \%$ in low/middle-income countries, $66.7 \%$ in highincome countries, $62.0-72.8 \%$ IQR), again with the exception of Israel in addition to Murcia in Spain. It is noteworthy that rates of comorbid anxiety disorder among respondents with MDD (reported Table 1) were comparatively low in both Israel and Murcia (21.9-32.0\% compared with IQR 32.0-46.5\%). 
Table 3. Socio-demographic correlates of lifetime and 12-month DSM-IV/CIDI MDD and of comorbid anxiety disorders ${ }^{a}$ given MDD in the WHO WMH Surveys ${ }^{b}$

\begin{tabular}{|c|c|c|c|c|c|c|c|c|}
\hline & \multicolumn{4}{|c|}{ Lifetime } & \multicolumn{4}{|c|}{ 12-Month } \\
\hline & \multicolumn{2}{|c|}{ MDD } & \multicolumn{2}{|c|}{$\begin{array}{l}\text { Anxiety disorder/ } \\
\text { MDD }\end{array}$} & \multicolumn{2}{|r|}{ MDD } & \multicolumn{2}{|c|}{$\begin{array}{l}\text { Anxiety disorder/ } \\
\text { MDD }\end{array}$} \\
\hline & OR & $(95 \% \mathrm{CI})$ & OR & $(95 \% \mathrm{CI})$ & OR & $(95 \% \mathrm{CI})$ & OR & $(95 \% \mathrm{CI})$ \\
\hline \multicolumn{9}{|l|}{ Age } \\
\hline $18-34$ & $1.4^{*}$ & $(1.25-1.52)$ & $1.8^{*}$ & $(1.56-2.09)$ & $2.1^{*}$ & $(1.78-2.42)$ & $2.6^{*}$ & $(2.03-3.24)$ \\
\hline $35-49$ & $1.9^{*}$ & $(1.73-2.06)$ & $2.6^{*}$ & $(2.29-2.96)$ & $2.5^{*}$ & $(2.16-2.84)$ & $3.3^{*}$ & $(2.67-4.07)$ \\
\hline $50-64$ & $1.7^{*}$ & $(1.55-1.85)$ & $2.2^{*}$ & $(1.93-2.49)$ & $1.9^{*}$ & $(1.68-2.21)$ & $2.6^{*}$ & $(2.14-3.24)$ \\
\hline $65+$ & 1.0 & - & 1.0 & - & 1.0 & - & 1.0 & - \\
\hline $\begin{array}{l}\chi_{3}^{2} \\
\text { Gender }\end{array}$ & $256.9^{*}$ & & $247.2^{*}$ & & $172.8^{*}$ & & $126.0^{*}$ & \\
\hline Male & 1.0 & - & 1.0 & - & 1.0 & - & 1.0 & - \\
\hline Female & $1.8^{*}$ & $(1.73-1.91)$ & $2.1^{*}$ & $(1.97-2.28)$ & $1.8^{*}$ & $(1.66-1.96)$ & $2.1^{*}$ & $(1.83-2.36)$ \\
\hline $\begin{array}{l}\chi_{1}^{2} \\
\text { Marital status }\end{array}$ & \multicolumn{8}{|c|}{ Marital status } \\
\hline Married & 1.0 & - & 1.0 & - & 1.0 & - & 1.0 & - \\
\hline Never Married & $1.2^{*}$ & $(1.07-1.23)$ & $1.2^{*}$ & $(1.04-1.27)$ & $1.4^{*}$ & $(1.22-1.49)$ & $1.4^{*}$ & $(1.23-1.69)$ \\
\hline Sep/Wid/Divorced & $2.0^{*}$ & $(1.90-2.19)$ & $2.0^{*}$ & $(1.81-2.19)$ & $2.2^{*}$ & $(1.97-2.42)$ & $2.3^{*}$ & $(2.01-2.72)$ \\
\hline $\begin{array}{l}\chi_{2}^{2} \\
\text { Income }^{c}\end{array}$ & $387.5^{*}$ & & $203.1^{*}$ & & $237.5^{*}$ & & $128.5^{*}$ & \\
\hline Low & 1.1 & $(0.99-1.15)$ & $1.3^{*}$ & $(1.16-1.43)$ & $1.4^{*}$ & $(1.23-1.54)$ & $1.6^{*}$ & $(1.36-1.89)$ \\
\hline Low-Mid & $1.1^{*}$ & $(1.05-1.22)$ & $1.3^{*}$ & $(1.20-1.47)$ & $1.3^{*}$ & $(1.19-1.49)$ & $1.6^{*}$ & $(1.31-1.83)$ \\
\hline Mid-High & $1.1^{*}$ & $(1.05-1.20)$ & $1.3^{*}$ & $(1.15-1.39)$ & $1.2^{*}$ & $(1.05-1.30)$ & $1.3^{*}$ & $(1.08-1.49)$ \\
\hline High & 1.0 & - & 1.0 & - & 1.0 & - & 1.0 & - \\
\hline$\chi_{3}^{2}$ & $15.3^{*}$ & & $36.6^{*}$ & & $37.3^{*}$ & & $36.5^{*}$ & \\
\hline \multicolumn{9}{|l|}{ Education level } \\
\hline None & $0.7^{*}$ & $(0.59-0.88)$ & $0.7^{*}$ & $(0.51-0.93)$ & 1.0 & $(0.75-1.37)$ & 0.9 & $(0.58-1.40)$ \\
\hline Some primary & $0.9^{*}$ & $(0.79-0.98)$ & 0.9 & $(0.79-1.08)$ & $1.2^{*}$ & $(1.03-1.42)$ & 1.2 & $(0.98-1.53)$ \\
\hline Completed primary & $0.7^{*}$ & $(0.64-0.80)$ & $0.8^{*}$ & $(0.66-0.90)$ & 0.9 & $(0.74-1.04)$ & 1.0 & $(0.78-1.29)$ \\
\hline Some secondary & $0.8^{*}$ & $(0.72-0.85)$ & $0.9^{*}$ & $(0.76-0.97)$ & $0.9^{*}$ & $(0.76-0.99)$ & 0.9 & $(0.77-1.16)$ \\
\hline Completed secondary & $0.8^{*}$ & $(0.70-0.82)$ & $0.8^{*}$ & $(0.68-0.84)$ & $0.8^{*}$ & $(0.72-0.91)$ & $0.8^{*}$ & $(0.62-0.90)$ \\
\hline Some College & 1.0 & $(0.87-1.04)$ & 1.0 & $(0.91-1.15)$ & 1.0 & $(0.91-1.19)$ & 1.1 & $(0.87-1.29)$ \\
\hline Completed college & 1.0 & - & 1.0 & - & 1.0 & - & 1.0 & - \\
\hline$\chi_{6}^{2}$ & $85.3^{*}$ & & $51.0^{*}$ & & $46.2^{*}$ & & $32.3^{*}$ & \\
\hline$n$ & 74045 & & 430 & & 74045 & & 5898 & \\
\hline
\end{tabular}

*Significant at the 0.05 level, two-sided test.

${ }^{a}$ Anxiety disorders include generalised anxiety disorder, panic disorder with or without agoraphobia, agoraphobia without a history of panic disorder, specific phobia, social phobia, separation anxiety and post-traumatic stress disorder.

${ }^{b}$ Based on person-level logistic regression models pooled across surveys. Time-varying socio-demographic variables were coded as of time of interview rather than as of AOO.

'Income was coded within country. Low $=$ less than $50 \%$ of the median value of the ratio of before-tax income to number of family members; Low-average $=50-100 \%$ of the median value of the ratio of before-tax income to number of family members; High-average $=$ more than $100 \%$ to $300 \%$ of the median value of the ratio of before-tax income to number of family members; High $=$ more than $300 \%$ of the median value of the ratio of before-tax income to number of family members.

\section{Socio-demographic correlates}

Significantly higher rates of lifetime MDD were found among respondents in middle age (ages 35-64) compared with ages $65+(\mathrm{OR}=1.7-1.9)$, women compared with men $(\mathrm{OR}=1.8)$, the previously-married compared with currently-married $(\mathrm{OR}=2.0)$, and those with less than high incomes compared with those with high incomes $(\mathrm{OR}=1.1)$. (Table 3) Slightly lower lifetime prevalence of MDD was found among respondents with less than some college education compared with 
those with at least some college education $(\mathrm{OR}=0.7-0.9)$. Country-specific analyses (available online) showed that the most consistent of these associations were being female (significant in 23 surveys, OR IQR 1.6-2.2) and previously married (significant in 24 surveys, OR IQR 1.8-2.4). The elevated ORs associated with being middle-aged were significant in 13 surveys (OR IQR 1.7-2.9). The associations of income and education with lifetime MDD were inconsistent across surveys.

Significant associations of these same sociodemographic variables were found with comorbid anxiety disorders among respondents with lifetime MDD, but the ORs for age, sex and income were higher than in predicting lifetime MDD: $\mathrm{OR}=1.8-2.7$ for ages 18-44 compared with $65+$; $O R=2.1$ for women compared with men; and $\mathrm{OR}=1.3$ for low compared with high income. ORs associated with marital status and education were virtually identical to those predicting lifetime MDD. Country-specific analyses (results available online) showed that the most consistently elevated ORs predicting comorbid anxiety among people with MDD were being female (significant in 22 surveys, OR IQR 1.7-2.7) and previously married (significant in 15 surveys, OR IQR 1.52.1). The elevated ORs associated with being middle-aged were significant in 15 surveys (OR IQR 2.1-4.2), while the associations of income and education with lifetime anxious $v$. non-anxious MDD were inconsistent across surveys.

Socio-demographics were also significantly associated with 12-month MDD. The positive ORs of young age, not being married, low to high-average income, and less than college education were consistently somewhat larger than those of the same predictors with lifetime MDD. The OR associated with female gender, in comparison, was identical in predicting lifetime and 12-month MDD $(\mathrm{OR}=1.8)$, indicating that women did not differ significantly from men in 12-month prevalence among lifetime cases. Broadly similar patterns were also found in predicting 12-month anxious MDD $v$. nonanxious MDD in that the ORs were all significant as a set (albeit with some ORs for specific education categories not significant even though education was significant overall $\left.\left[\chi_{6}^{2}=32.3, p<0.001\right]\right)$ and either equal or higher in magnitude than those associated with MDD in the total sample. This means that these socio-demographics were all more strongly associated with persistence of anxious MDD than persistence of non-anxious MDD. The results of more detailed within-country analyses were unstable due to small numbers of cases (results available online).

\section{Severity of anxious v. non-anxious MDD}

The proportion of respondents with 12-month MDD who reported severe role impairment was significantly higher in the presence $(64.4 \%)$ than absence $(46.0 \%)$ of 12-month anxiety disorders $\left(\chi_{1}^{2}=187.0, p<0.001\right)$. (Table 4) Very similar overall patterns were found in low/middle-income countries $\left(61.5 \%\right.$ v. $41.9 \%$; $\chi_{1}^{2}=$ 97.5, $p<0.001)$ and high-income countries $(68.8 \% v$. $\left.49.6 \% ; \chi_{1}^{2}=128.0, p<0.001\right)$ although the pattern was less consistent in low/middle-income countries (7 of 12 surveys, 6 statistically significant) than high-income countries (all 15 surveys, 10 significant).

The proportion of respondents with 12-month MDD who reported suicide ideation was also significantly higher in the presence $(19.5 \%)$ than absence $(8.9 \%)$ of 12 -month anxiety disorders $\left(\chi_{1}^{2}=71.6, p<0.001\right)$. Very similar patterns were found in low/middle-income countries $\left(15.2 \%\right.$ v. 9.4\%; $\left.\chi_{1}^{2}=7.9, p=0.005\right)$ and highincome countries (21.3 v. 8.7\%; $\left.\chi_{1}^{2}=72.8, p<0.001\right)$ overall, although consistency of the pattern was again somewhat lower in low/middle-income countries (9 of 12 surveys, 3 statistically significant) than high-income countries (14 of 15 surveys, 13 significant).

\section{Treatment}

Twelve-month treatment of MDD was significantly more common in the presence than absence of 12 -month anxiety disorders $\left(56.2 \%\right.$ v. $37.3 \% ; \chi_{1}^{2}=21.8$, $p<0.001$ ). (Table 5) Very similar relative treatment rates were found in low/middle income $(30.3 \% \mathrm{v}$. $\left.20.6 \% ; \chi_{1}^{2}=11.7, p<0.001\right)$ and high income $(66.8 \% v$. $\left.45.4 \% ; \chi_{1}^{2}=108.8, p<0.001\right)$ countries (i.e., respondents with anxious MDD were roughly $50 \%$ more likely to receive treatment than those with non-anxious MDD). However, the absolute difference in treatment rates was much higher in high-income (a 23.4\% higher treatment rate of anxious than non-anxious MDD [68.8-45.4\%]) than low/middle-income (a 9.7\% higher treatment rate of anxious than non-anxious MDD [30.3-20.6\%]) countries due to the overall treatment rate being much higher in high income than low/ middle-income countries. The pattern of higher treatment of anxious than non-anxious MDD was also more consistent in high-income (all 15 surveys, 10 significant) than low/middle-income (9 of 12 surveys, 3 significant) countries. Similarly significant patterns were found in separate treatment sectors other than the nonmedical sector in low/middle-income countries $\left(\chi_{1}^{2}=4.7-7.5 ; p=0.030-0.006\right)$ and in all sectors in highincome countries $\left(\chi_{1}^{2}=36.6-77.1 ; p<0.001\right)$.

\section{Discussion}

The above results are limited by between-survey differences in response rates and sample frames (most 
Table 4. Two indicators of severity (proportion of cases reporting severe role impairment due to depression and proportion of cases reporting suicide ideation) among respondents with 12-month DSM-IV/CIDI MDD depending on presence or absence of comorbid anxiety disorders ${ }^{a}$ in the WHO WMH Surveys

\begin{tabular}{|c|c|c|c|c|c|c|c|c|c|c|}
\hline & \multicolumn{4}{|c|}{$\begin{array}{l}\text { Prevalence of severe } \\
\text { role impairment }{ }^{\mathrm{b}} \text { when comorbid } \\
\text { anxiety disorders are ... }\end{array}$} & \multicolumn{4}{|c|}{$\begin{array}{c}\text { Prevalence of suicide } \\
\text { ideation }^{c} \text { when comorbid } \\
\text { anxiety disorders are ... }\end{array}$} & \multicolumn{2}{|c|}{$\begin{array}{c}\text { Number of } \\
\text { respondents with } \\
\text { 12-month MDD } \\
\text { where comorbid } \\
\text { anxiety disorders } \\
\text { are ... }\end{array}$} \\
\hline & \multicolumn{2}{|c|}{ Present } & \multicolumn{2}{|c|}{ Absent } & \multicolumn{2}{|c|}{ Present } & \multicolumn{2}{|c|}{ Absent } & \multirow{2}{*}{$\frac{\text { Present }}{(\mathrm{n})}$} & \multirow{2}{*}{$\frac{\text { Absent }}{(\mathrm{n})}$} \\
\hline & $\%$ & (S.E.) & $\%$ & (S.E.) & $\%$ & (S.E.) & $\%$ & (S.E.) & & \\
\hline \multicolumn{11}{|l|}{ I. Low/Middle Income } \\
\hline Brazil - São Paulo & $57.0^{*}$ & (3.5) & 41.2 & $(2.9)$ & $18.7^{*}$ & (3.4) & 7.1 & $(1.6)$ & (205) & $(284)$ \\
\hline Bulgaria & $51.7^{*}$ & (6.9) & 41.5 & $(5.2)$ & $8.7^{*}$ & $(4.5)$ & 16.1 & $(6.7)$ & $(54)$ & $(91)$ \\
\hline Colombia & $49.3^{*}$ & $(4.8)$ & 42.1 & $(4.8)$ & $20.8^{*}$ & (5.9) & 13.5 & (3.6) & $(110)$ & $(131)$ \\
\hline Colombia - Medellin & 51.0 & $(5.9)$ & 51.1 & $(5.7)$ & 21.3 & $(5.8)$ & 18.5 & $(5.3)$ & (73) & (78) \\
\hline Iraq & $71.8^{*}$ & $(5.0)$ & 36.3 & $(4.8)$ & $11.8^{*}$ & $(5.9)$ & 4.7 & $(1.8)$ & $(81)$ & $(101)$ \\
\hline Lebanon & 63.3 & $(7.0)$ & 64.5 & $(5.5)$ & $5.3^{*}$ & $(3.8)$ & 9.2 & $(3.9)$ & $(49)$ & $(77)$ \\
\hline Mexico & $45.2^{*}$ & $(5.0)$ & 38.6 & $(4.3)$ & 16.4 & $(4.3)$ & 15.9 & $(3.9)$ & $(101)$ & $(130)$ \\
\hline Nigeria & 8.0 & $(8.2)$ & 16.2 & $(4.8)$ & 20.8 & $(18.2)$ & 17.7 & $(6.5)$ & $(12)$ & $(60)$ \\
\hline Peru & 35.3 & $(8.0)$ & 39.7 & (6.3) & $6.9^{*}$ & $(4.7)$ & 18.3 & $(5.0)$ & (37) & (62) \\
\hline PRC $^{d}$ - Beijing/Shanghai & 22.1 & (9.3) & 32.2 & $(5.8)$ & 8.2 & $(5.8)$ & 4.2 & $(2.8)$ & $(21)$ & (66) \\
\hline PRC $^{\mathrm{d}}$ - Shenzhen & $41.1^{*}$ & $(8.2)$ & 19.4 & $(2.9)$ & 5.0 & $(2.9)$ & 3.2 & $(1.6)$ & (37) & (185) \\
\hline Romania & 46.9 & $(15.8)$ & 40.8 & (9.3) & 5.0 & $(5.4)$ & 4.6 & $(4.6)$ & (11) & $(29)$ \\
\hline Total & $61.5^{*}$ & $(1.5)$ & 41.9 & $(1.3)$ & $15.2^{*}$ & $(1.8)$ & 9.4 & $(1.0)$ & $(791)$ & (1294) \\
\hline \multicolumn{11}{|l|}{ II. High Income } \\
\hline Australia & $77.3^{*}$ & $(2.8)$ & 52.4 & $(3.4)$ & $24.9^{*}$ & $(3.9)$ & 7.1 & $(1.7)$ & $(229)$ & $(217)$ \\
\hline Belgium & 66.0 & $(12.6)$ & 52.4 & (9.6) & 12.7 & $(5.2)$ & 10.9 & $(5.0)$ & $(39)$ & $(67)$ \\
\hline France & 67.2 & $(8.4)$ & 49.3 & (7.9) & $19.3^{*}$ & (6.3) & 7.0 & $(2.8)$ & (68) & (89) \\
\hline Germany & 64.5 & (9.6) & 54.2 & $(8.7)$ & $19.1^{*}$ & $(6.2)$ & 2.1 & (1.5) & (55) & (54) \\
\hline Israel & $70.8^{*}$ & $(6.6)$ & 51.2 & (3.3) & $15.3^{*}$ & $(5.5)$ & 9.7 & $(2.0)$ & $(48)$ & $(232)$ \\
\hline Italy & 59.8 & $(11.8)$ & 53.6 & $(8.9)$ & $10.8^{*}$ & $(4.4)$ & 5.0 & $(2.4)$ & $(51)$ & (67) \\
\hline Japan & $68.9^{*}$ & (9.4) & 28.5 & $(6.1)$ & $32.7^{*}$ & $(11.0)$ & 6.9 & $(3.6)$ & $(25)$ & $(56)$ \\
\hline Netherlands & 68.1 & $(14.7)$ & 55.7 & $(9.4)$ & 19.0 & $(7.2)$ & 14.1 & $(9.0)$ & $(40)$ & $(81)$ \\
\hline New Zealand & $73.2^{*}$ & $(2.3)$ & 56.2 & (2.6) & $28.9^{*}$ & (3.3) & 14.7 & $(2.3)$ & $(370)$ & (365) \\
\hline Northern Ireland & $62.6^{*}$ & $(4.6)$ & 51.1 & $(4.8)$ & $14.7^{*}$ & (3.7) & 1.2 & $(0.9)$ & $(110)$ & (109) \\
\hline Poland & $56.5^{*}$ & (8.4) & 41.7 & (5.3) & $18.5^{*}$ & $(7.0)$ & 8.4 & (3.3) & (36) & (87) \\
\hline Portugal & $59.3^{*}$ & $(4.4)$ & 42.1 & (3.9) & $13.5^{*}$ & (3.1) & 8.7 & $(2.4)$ & $(126)$ & $(164)$ \\
\hline Spain & 61.8 & (8.4) & 52.6 & $(7.6)$ & 6.8 & (3.0) & 7.3 & $(2.7)$ & (87) & $(142)$ \\
\hline Spain - Murcia & $50.8^{*}$ & (7.5) & 36.4 & $(4.6)$ & $15.2^{*}$ & $(6.0)$ & 6.8 & $(2.9)$ & $(45)$ & (109) \\
\hline US & $67.0^{*}$ & $(2.4)$ & 46.0 & $(3.0)$ & $21.5^{*}$ & $(2.4)$ & 7.8 & $(1.7)$ & (375) & $(271)$ \\
\hline Total & $68.8^{*}$ & (1.2) & 49.6 & (1.2) & $21.3^{*}$ & (1.3) & 8.7 & $(0.7)$ & (1704) & (2110) \\
\hline III. Total & $64.4^{*}$ & $(1.0)$ & 46.0 & $(0.9)$ & $19.5^{*}$ & (1.1) & 8.9 & $(0.6)$ & (2495) & $(3404)$ \\
\hline
\end{tabular}

*Significant difference depending on whether comorbid anxiety disorders are present $v$. absent at the 0.05 level, two-sided test.

${ }^{a}$ Anxiety disorders include generalised anxiety disorder, panic disorder with or without agoraphobia, agoraphobia without a history of panic disorder, specific phobia, social phobia, separation anxiety and post-traumatic stress disorder.

${ }^{b}$ Ratings of severe or very severe on one or more SDS dimensions in the 1 month in the 12 before interview when the respondent's MDD was most severe.

cAt any time in the 12 months before interview.

dPeople's Republic of China. 
Table 5. Treatment of 12-month DSM-IV/CIDI MDD in the presence v. absence of comorbid anxiety disorders ${ }^{a}$ in the WHO WMH Surveys ${ }^{b}$

\begin{tabular}{|c|c|c|c|c|c|c|c|c|c|c|c|c|c|c|c|c|}
\hline & \multicolumn{4}{|c|}{ Any } & \multicolumn{4}{|c|}{ Specialty Psychiatric $^{\mathrm{C}}$} & \multicolumn{4}{|c|}{ General Medical $^{\mathrm{c}}$} & \multicolumn{4}{|c|}{ Non-medical ${ }^{c}$} \\
\hline & \multicolumn{2}{|c|}{ Present } & \multicolumn{2}{|c|}{ Absent } & \multicolumn{2}{|c|}{ Present } & \multicolumn{2}{|c|}{ Absent } & \multicolumn{2}{|c|}{ Present } & \multicolumn{2}{|c|}{ Absent } & \multicolumn{2}{|c|}{ Present } & \multicolumn{2}{|c|}{ Absent } \\
\hline & $\%$ & (S.E.) & $\%$ & (S.E.) & $\%$ & (s.E.) & $\%$ & (S.E.) & $\%$ & (S.E.) & $\%$ & (S.E.) & $\%$ & (s.Е.) & $\%$ & (S.E.) \\
\hline \multicolumn{17}{|l|}{ I. Low/Middle Income } \\
\hline Brazil - São Paulo & $43.9^{*}$ & (4.5) & 30.4 & (3.5) & 27.2 & $(4.0)$ & 17.7 & $(2.8)$ & 19.4 & (3.7) & 12.6 & $(2.6)$ & 9.6 & $(2.9)$ & 9.1 & $(2.3)$ \\
\hline Bulgaria & 39.7 & (8.1) & 27.8 & $(6.1)$ & 13.9 & $(5.7)$ & 8.7 & (3.9) & 34.6 & $(8.0)$ & 22.7 & $(5.6)$ & 0.5 & $(0.5)$ & 0.9 & $(0.9)$ \\
\hline Colombia & 24.2 & (5.9) & 16.4 & (3.7) & 17.3 & (5.6) & 8.7 & $(2.7)$ & 6.2 & $(2.2)$ & 6.9 & (2.5) & 5.6 & (3.9) & 1.7 & (1.1) \\
\hline Colombia - Medellin & 28.6 & (6.1) & 26.9 & $(6.1)$ & 15.5 & $(4.9)$ & 24.2 & (5.9) & 11.4 & $(4.1)$ & 4.9 & $(2.8)$ & 5.9 & $(2.9)$ & 1.0 & $(1.0)$ \\
\hline Iraq & 16.5 & (7.6) & 8.4 & $(4.3)$ & 7.0 & (5.7) & 5.8 & $(4.2)$ & 2.6 & (1.5) & 0.5 & $(0.4)$ & 7.0 & (5.6) & 2.1 & $(1.0)$ \\
\hline Lebanon & 18.2 & (6.1) & 26.0 & (5.9) & 7.4 & (4.2) & 13.0 & (5.1) & 11.8 & (5.3) & 13.1 & $(4.0)$ & 2.0 & (1.5) & 1.8 & (1.5) \\
\hline Mexico & 18.9 & (4.6) & 30.7 & (4.7) & 11.0 & $(4.0)$ & 12.8 & (3.4) & $5.7^{*}$ & (1.9) & 13.8 & (3.5) & 6.1 & (3.6) & 5.8 & $(2.2)$ \\
\hline Nigeria & $58.5^{*}$ & $(18.1)$ & 10.1 & (5.7) & 3.0 & (3.2) & 2.8 & (2.1) & $47.6^{*}$ & $(18.1)$ & 8.3 & (5.5) & 8.0 & $(8.2)$ & 1.7 & $(1.8)$ \\
\hline Peru & 25.9 & $(7.4)$ & 33.2 & (6.6) & 6.7 & (4.2) & 19.6 & (5.3) & 12.5 & $(5.5)$ & 12.0 & (4.9) & 12.8 & (5.7) & 8.7 & (3.8) \\
\hline PRC $^{\mathrm{d}}-$ Beijing/Shanghai & $56.2^{*}$ & $(18.5)$ & 7.2 & $(4.4)$ & 3.9 & $(4.1)$ & 6.2 & $(4.4)$ & $54.8^{*}$ & $(18.9)$ & 0.6 & $(0.6)$ & 37.5 & $(24.1)$ & 0.5 & $(0.5)$ \\
\hline $\mathrm{PRC}^{\mathrm{d}}$ - Shenzhen & 14.1 & $(7.0)$ & 5.9 & $(2.3)$ & 9.9 & $(6.4)$ & 0.2 & $(0.2)$ & 9.5 & $(6.4)$ & 0.7 & $(0.4)$ & 2.5 & $(2.6)$ & 5.3 & $(2.2)$ \\
\hline Romania & 48.5 & $(19.7)$ & 12.0 & $(6.4)$ & 30.4 & $(19.8)$ & 7.5 & (5.5) & 25.1 & $(13.2)$ & 8.3 & (5.9) & - & - & 1.2 & (1.3) \\
\hline Total & $30.3^{*}$ & $(2.4)$ & 20.6 & $(1.5)$ & $16.1^{*}$ & $(1.9)$ & 11.2 & $(1.2)$ & $14.0^{*}$ & $(1.7)$ & 8.6 & $(1.0)$ & $7.5^{*}$ & $(1.7)$ & 4.6 & $(0.7)$ \\
\hline \multicolumn{17}{|l|}{ II. High Income } \\
\hline Australia & $80.2^{*}$ & $(2.6)$ & 47.0 & $(3.4)$ & $54.4^{*}$ & $(3.3)$ & 22.6 & $(2.8)$ & $61.9^{*}$ & $(3.2)$ & 34.1 & $(3.2)$ & $20.0^{*}$ & (2.6) & 6.9 & (1.7) \\
\hline Belgium & 61.4 & $(10.1)$ & 49.3 & (8.6) & 34.1 & (9.1) & 34.4 & (8.5) & 49.4 & $(10.1)$ & 40.5 & (8.6) & 9.1 & (6.2) & 2.6 & (2.0) \\
\hline France & $62.2^{*}$ & $(8.5)$ & 36.4 & (6.4) & 28.7 & (8.6) & 14.7 & $(4.8)$ & $49.7^{*}$ & $(8.1)$ & 29.3 & (5.7) & 0.5 & $(0.6)$ & 2.8 & (1.6) \\
\hline Germany & 51.6 & (7.5) & 43.8 & (8.5) & $39.2^{*}$ & (7.3) & 17.6 & (5.6) & 21.2 & (6.5) & 33.8 & $(8.2)$ & 10.4 & $(4.2)$ & 5.9 & (3.3) \\
\hline Israel & $55.8^{*}$ & (7.5) & 35.5 & (3.3) & $36.4^{*}$ & (7.3) & 19.7 & $(2.7)$ & $35.0^{*}$ & (7.3) & 14.8 & $(2.4)$ & 15.7 & (5.6) & 8.4 & $(1.8)$ \\
\hline Italy & $64.3^{*}$ & $(7.2)$ & 20.2 & (4.9) & 21.8 & (7.2) & 9.9 & (3.8) & $61.4^{*}$ & (7.4) & 16.8 & (4.7) & 3.1 & (2.2) & 2.2 & (1.6) \\
\hline Japan & $60.0^{*}$ & $(11.1)$ & 32.4 & (8.3) & 46.6 & (11.9) & 20.4 & (6.6) & 18.1 & $(9.6)$ & 9.7 & (7.0) & $34.0^{*}$ & $(11.7)$ & 7.9 & $(4.3)$ \\
\hline Netherlands & $77.4^{*}$ & $(7.7)$ & 36.8 & (7.7) & $52.7^{*}$ & (10.5) & 17.9 & (4.5) & $63.8^{*}$ & $(10.0)$ & 27.3 & (7.1) & 10.3 & (5.3) & 3.7 & (1.8) \\
\hline New Zealand & $64.7^{*}$ & (3.3) & 53.4 & (3.5) & $30.9^{*}$ & $(3.1)$ & 21.7 & (2.8) & 46.8 & (3.3) & 42.1 & (3.4) & $19.9^{*}$ & $(2.8)$ & 9.9 & (1.9) \\
\hline Northern Ireland & $61.3^{*}$ & (6.2) & 41.0 & (6.1) & 25.2 & (4.7) & 11.4 & (4.1) & $59.6^{*}$ & (6.2) & 38.2 & $(6.0)$ & 9.4 & (3.2) & 6.8 & (3.6) \\
\hline Poland & 49.8 & (9.7) & 36.2 & $(6.0)$ & 33.2 & $(8.8)$ & 25.3 & (5.1) & 28.7 & (9.4) & 16.6 & $(4.7)$ & 12.0 & (5.6) & 7.7 & (3.5) \\
\hline Portugal & 60.8 & (4.9) & 55.4 & (4.4) & 32.8 & (4.6) & 25.2 & (3.9) & 41.0 & (4.9) & 36.6 & (4.3) & 6.9 & (2.4) & 3.5 & (1.7) \\
\hline Spain & $70.2^{*}$ & (6.1) & 51.6 & (5.6) & 33.4 & (6.5) & 40.2 & (5.3) & $59.1^{*}$ & (6.6) & 24.8 & $(4.3)$ & 6.2 & $(4.0)$ & 2.3 & $(1.0)$ \\
\hline Spain - Murcia & 73.9 & (7.8) & 61.8 & (5.9) & $56.9^{*}$ & (8.7) & 33.6 & $(6.2)$ & 21.0 & (6.3) & 33.0 & (5.6) & 4.9 & (3.7) & 1.1 & $(0.7)$ \\
\hline US & $63.5^{*}$ & $(2.8)$ & 48.6 & (3.3) & $37.7^{*}$ & $(2.9)$ & 26.0 & (2.8) & $38.0^{*}$ & $(2.9)$ & 26.4 & (3.0) & 19.1 & (2.3) & 14.9 & $(2.3)$ \\
\hline Total & $66.8^{*}$ & (1.5) & 45.4 & (1.4) & $38.5^{*}$ & (1.6) & 22.6 & $(1.2)$ & $47.7^{*}$ & (1.6) & 29.6 & (1.3) & $15.8^{*}$ & $(1.2)$ & 7.4 & $(0.7)$ \\
\hline
\end{tabular}




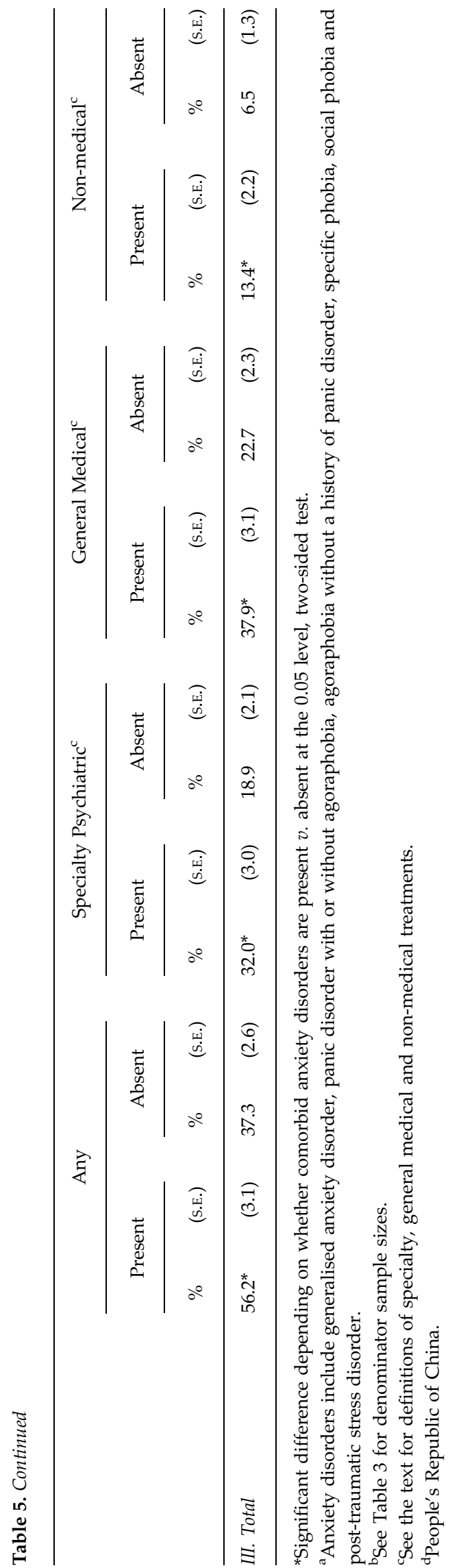

notably, underrepresentation of rural areas in developing countries), diagnoses being based on fully structured lay interviews rather than semi-structured clinician-administered interviews (although available evidence documents good concordance between the two types of diagnoses in WMH; Haro et al. 2006), the fact that we examined only a summary measure of any DSM-IV anxiety disorder rather than disaggregated disorder-specific measures, and the fact that the WMH surveys were cross-sectional. The latter limitation meant that both lifetime prevalence and $\mathrm{AOO}$ were assessed retrospectively. Previous methodological studies (Moffitt et al. 2010; Hamdi \& Iacono, 2014; Takayanagi et al. 2014) suggest that use of retrospective recall probably led to underestimation of lifetime prevalence and overestimation of persistence. Long-term prospective studies are needed to resolve this problem.

Within the context of these limitations, we found a relatively narrow IQR across surveys (32.0-46.5\%) in estimated rates of lifetime anxiety disorders among people with lifetime MDD, somewhat higher rates but an equally narrow IQR $(37.8-54.0 \%)$ of lifetime comorbid anxiety disorders among respondents with 12-month MDD, and only slightly lower rates with a similarly narrow IQR (29.9-47.2\%) of 12-month comorbid anxiety disorders among respondents with 12-month MDD. The fact that lifetime comorbid anxiety disorders were more prevalent among respondents with 12-month than lifetime MDD suggests that lifetime comorbid anxiety disorders predict MDD persistence, while the fact that 12-month comorbid anxiety disorders were only slightly less prevalent than lifetime comorbid anxiety disorders among respondents with 12-month MDD suggests that anxiety disorder persistence is positively associated with MDD persistence. These patterns are broadly consistent with previous epidemiological studies (Andrade et al. 2003; Kessler et al. 2011b; Lamers et al. 2011). We are unaware, although, of previous studies that examined either the differences we did in the magnitudes of lifetime comorbidity, 12-month comorbidity or comorbidity between lifetime anxiety disorders and 12-month MDD. Our results also go beyond previous studies in documenting considerable cross-national consistency in comorbidity between anxiety disorders and MDD.

The socio-demographic associations documented here are broadly consistent with previous studies in finding higher rates of both anxiety disorders and MDD among women (Parker \& Brotchie, 2010; Altemus et al. 2014) and the previously married (Scott et al. 2010; Leach et al. 2013) along with less consistent inverse associations with age (de Graaf et al. 2013; McDowell et al. 2014). However, we are unaware 
of prior systematic efforts to examine nested associations in the way we did here. It is noteworthy, although, that we did not examine disaggregated associations (e.g., the extent to which socio-demographics predict onset of secondary MDD among people with a history of temporally primary anxiety disorders). The strength and consistency of the associations we documented across nested outcomes suggest that more detailed studies of these specifications might be useful.

Our finding of higher role impairment and suicidality in anxious than non-anxious MDD is broadly consistent with previous findings (Roy-Byrne et al. 2000; McLaughlin et al. 2006; Ormel et al. 2008), although we showed that this pattern generalises to many more countries than in previous research. We found stronger and more consistent associations of comorbid anxiety disorders with elevated MDD treatment rates in highincome than low/middle-income countries. Previous studies of this pattern, which were limited to highincome Western countries (Kessler et al. 2001; Jacobi et al. 2004), found similar associations with those in the high-income WMH Surveys. The overrepresentation of anxious MDD in treatment populations is important because comorbid anxiety disorders predict both low MDD treatment persistence (Shippee et al. 2014) and low MDD treatment response (Stiles-Shields et al. 2014).

Our finding that the vast majority of WMH respondents with anxious MDD reported earlier AOO of anxiety disorders than MDD is consistent with previous research in both cross-sectional/retrospective (Kessler, 1995; Kessler et al. 2011a) and prospective (Murphy et al. 1986; Bittner et al. 2004; Copeland et al. 2009; Klein et al. 2013) samples. The narrow IQR of the proportion of respondents who reported earlier AOO of anxiety disorders than MDD (69.6-74.7\%) is especially noteworthy. It is also striking, although, that these proportions are not higher among respondents with 12-month than lifetime comorbidity, as we might expect the latter rates to be higher if temporally primary comorbid anxiety was more important than temporally secondary comorbid anxiety in predicting MDD persistence. We are unaware of any previous research on this distinction. The finding that comorbid anxiety disorder is related to MDD persistence equally whether or not the anxiety is temporally primary might reflect influences of common underlying causes accounting for the lifetime comorbidities of MDD with anxiety disorders, although another possibility consistent with this pattern is that the causal processes accounting for the effects of anxiety disorders on MDD onset differ from the causal processes accounting for the effects of anxiety disorders on MDD persistence. We have no way to adjudicate between these competing possibilities with the WMH data.
If temporally primary anxiety disorders are causal risk factors for MDD, interventions to treat pure anxiety disorders would be expected to reduce subsequent onset of MDD. However, no well-controlled long-term treatment studies have evaluated this possibility despite calls to do so (Flannery-Schroeder, 2006; Garber \& Weersing, 2010). Consistent with this possibility, although, two observational studies based on community epidemiological surveys found that individuals who received treatment for temporally primary panic disorder (Goodwin \& Olfson, 2001) and generalised anxiety disorder (Goodwin \& Gorman, 2002) were significantly less likely than others with these disorders to go on to develop temporally secondary MDD. Although selection bias into treatment is a possible explanation for these patterns, the most plausible type of selection bias (i.e., selection into treatment based on severity) would be expected to lead to the opposite association with subsequent MDD, arguing indirectly for the possibility that treatment of anxiety disorders might lead to a reduction in risk of subsequent MDD. Other results consistent with this possibility include those from controlled studies of focused psychotherapy for anxiety disorders that showed these treatments reduced concurrent symptoms of MDD (reviewed in Hofmann \& Smits, 2008; Cuijpers et al. 2014), although this result is not entirely consistent (McLean et al. 1998; Woody et al. 1999). In addition, one small controlled study of CBT for social phobia among adolescent girls found that treatment reduced relapse of MDD among patients with a history of comorbid MDD over the subsequent year (Hayward et al. 2000).

Despite the suggestive evidence in the above studies, more definitive long-term controlled efficacy trials are needed to evaluate the impact of interventions to treat temporally primary anxiety disorders on the subsequent onset and persistence of MDD. An intriguing observation related to the need for this kind of definitive longterm controlled treatment study is that several epidemiological studies have found distinct risk factors for anxiety disorders that are not risk factors for MDD (Moffitt et al. 2007; Beesdo et al. 2010; Mathew et al. 2011; Asselmann et al. 2015). For example, an extensive literature shows that stressful life events associated with danger predict anxiety but not depression (Finlay-Jones \& Brown, 1981; Kendler et al. 2003; Asselmann et al. 2015). This specificity should not exist if anxiety disorders caused MDD, as the latter causal process would lead to attenuated associations of the risk factors with MDD. To find that this is not the case suggests that something more complex is at work linking anxiety disorders with MDD and that common causes are involved in the comorbidity of anxiety disorders with MDD.

The existence of common causes would impose an upper bound on how much secondary MDD could be 
prevented by successful treatment of temporally primary anxiety disorders. Common causes might also help account for the fact that concurrent comorbidity is associated with poor treatment response for both anxiety disorders (Rapee et al. 2013; Kelly et al. 2014) and MDD (Jakubovski \& Bloch, 2014; Saveanu et al. 2014). Less is known, although, about the associations of lifetime comorbidity with treatment response among patients who do not have concurrent comorbid symptoms. An examination of this specification would be useful in helping distinguish differential treatment response associated with the amelioration of life stressors surrounding particular anxious-MDD episodes and risk factors associated with more fundamental causes of lifetime anxious-MDD.

The latter suggestion highlights the fact that little research has attempting to distinguish the determinants of first onsets from the determinants of the subsequent course of either anxiety disorders or MDD. Virtually all the research cited above on the association between treating anxiety disorders and subsequent change in depression as well as on the associations of comorbidity with differential treatment response implicitly focused on the course of depression, as only a small minority of MDD cases in clinical studies are first-onset cases. As noted above, it is quite possible that different processes are at work in bringing about lifetime comorbidity and episode comorbidity. Research is needed to investigate such differences explicitly.

It is noteworthy in this regard that epidemiological research assuming the existence of common causes has shown that the coefficients describing the crosslagged prospective associations of temporally primary lifetime anxiety with subsequent first lifetime onset of MDD and vice versa can be parsimoniously described by assuming a latent intervening predisposition to all internalising disorders (Kessler et al. 2011a, b). Although some hypotheses have been advanced for asymmetries in these associations (Cummings et al. 2014), available evidence suggests that these asymmetries are weak. If this model is accurate, then temporally primary lifetime anxiety disorders might be risk markers rather than causal risk factors for the subsequent first onset of lifetime MDD even though anxiety disorders might have causal effects on the subsequent persistence of MDD. If this is the case, then successful intervention to treat early-onset primary anxiety disorders might not prevent the subsequent first onset of MDD even though it would reduce MDD persistence. A more consistent distinction between lifetime and concurrent comorbidity needs to be made in future observational and clinical studies of anxious MDD to shed light on these possibilities. As part of this increased focus, any attempt to carry out long-term controlled treatment studies to evaluate the effects of treating temporally primary anxiety on subsequent MDD should be designed to have a sufficiently large sample size and a sufficient duration of follow-up to examine effects on both MDD onset and MDD persistence and to include an assessment of plausible biomarkers. Our understanding of the causal determinants of the high comorbidity of MDD with anxiety disorders will remain at its current relatively primitive level until studies of this sort are carried out.

\section{Acknowledgement}

The authors appreciate the helpful contributions to WMH of Herbert Matschinger, PhD.

\section{Financial Support}

The WMH surveys were supported by the United States National Institute of Mental Health (R01MH070884), the John D. and Catherine T. MacArthur Foundation, the Pfizer Foundation, the US Public Health Service (R13-MH066849, R01-MH069864 and R01 DA016558), the Fogarty International Center (FIRCA R03-TW006481), the Pan American Health Organization, the Eli Lilly \& Company Foundation, Ortho-McNeil Pharmaceutical, Inc., GlaxoSmithKline, Bristol-Myers Squibb and Shire. The São Paulo Megacity Mental Health Survey is supported by the State of São Paulo Research Foundation (FAPESP) Thematic Project Grant 03/ 00204-3. The Bulgarian Epidemiological Study of common mental disorders EPIBUL is supported by the Ministry of Health and the National Center for Public Health Protection. The Chinese World Mental Health Survey Initiative is supported by the Pfizer Foundation. The Shenzhen Mental Health Survey is supported by the Shenzhen Bureau of Health and the Shenzhen Bureau of Science, Technology, and Information. The Colombian National Study of Mental Health (NSMH) is supported by the Ministry of Social Protection. The ESEMeD project is funded by the European Commission (Contracts QLG5-1999-01042; SANCO 2004123), the Piedmont Region (Italy), Fondo de Investigación Sanitaria, Instituto de Salud Carlos III, Spain (FIS 00/0028), Ministerio de Ciencia y Tecnología, Spain (SAF 2000-158-CE), Departament de Salut, Generalitat de Catalunya, Spain, Instituto de Salud Carlos III (CIBER CB06/02/0046, RETICS RD06/0011 REM-TAP), and other local agencies and by an unrestricted educational grant from GlaxoSmithKline. The WMHI was funded by WHO (India) and helped by Dr R Chandrasekaran, JIPMER. Implementation of the Iraq Mental Health Survey (IMHS) and data 
entry were carried out by the staff of the Iraqi $\mathrm{MOH}$ and MOP with direct support from the Iraqi IMHS team with funding from both the Japanese and European Funds through United Nations Development Group Iraq Trust Fund (UNDG ITF). The Israel National Health Survey is funded by the Ministry of Health with support from the Israel National Institute for Health Policy and Health Services Research and the National Insurance Institute of Israel. The World Mental Health Japan (WMHJ) Survey is supported by the Grant for Research on Psychiatric and Neurological Diseases and Mental Health (H13-SHOGAI-023, H14TOKUBETSU-026, H16-KOKORO-013) from the Japan Ministry of Health, Labour and Welfare. The Lebanese National Mental Health Survey (LEBANON) is supported by the Lebanese Ministry of Public Health, the WHO (Lebanon), Fogarty International, Act for Lebanon, anonymous private donations to IDRAAC, Lebanon, and unrestricted grants from Janssen Cilag, Eli Lilly, GlaxoSmithKline, Roche, and Novartis. The Mexican National Comorbidity Survey (MNCS) is supported by The National Institute of Psychiatry Ramon de la Fuente (INPRFMDIES 4280) and by the National Council on Science and Technology (CONACyT-G30544- H), with supplemental support from the PanAmerican Health Organization (PAHO). Te Rau Hinengaro: The New Zealand Mental Health Survey (NZMHS) is supported by the New Zealand Ministry of Health, Alcohol Advisory Council and the Health Research Council. The Nigerian Survey of Mental Health and Wellbeing (NSMHW) is supported by the WHO (Geneva), the WHO (Nigeria), and the Federal Ministry of Health, Abuja, Nigeria. The Romania WMH study projects 'Policies in Mental Health Area' and 'National Study regarding Mental Health and Services Use' were carried out by National School of Public Health \& Health Services Management (former National Institute for Research \& Development in Health), with technical support of Metro Media Transilvania, the National Institute of Statistics-National Centre for Training in Statistics, SC. Cheyenne Services SRL, Statistics Netherlands and were funded by Ministry of Public Health (former Ministry of Health) with supplemental support of Eli Lilly Romania SRL. The EZOP - Poland (Epidemiology of Mental Disorders and Access to Care) survey was supported by the grant from the EAA/Norwegian Financial Mechanisms as well as by the Polish Ministry of Health). The South Africa Stress and Health Study (SASH) is supported by the US National Institute of Mental Health (R01MH059575) and National Institute of Drug Abuse with supplemental funding from the South African
Department of Health and the University of Michigan. The US National Comorbidity Survey Replication (NCS-R) is supported by the National Institute of Mental Health (NIMH; U01-MH60220) with supplemental support from the National Institute of Drug Abuse (NIDA), the Substance Abuse and Mental Health Services Administration (SAMHSA), the Robert Wood Johnson Foundation (RWJF; Grant 044708), and the John W. Alden Trust.

\section{Statement of Interest}

In the past 3 years, Dr Kessler has been a consultant for Hoffman-La Roche, Inc., Johnson \& Johnson Wellness and Prevention, and Sonofi-Aventis Groupe. Dr Kessler has served on advisory boards for Mensante Corporation, Plus One Health Management, Lake Nona Institute, and U.S. Preventive Medicine. Dr Kessler owns 25\% share in DataStat, Inc. Dr Wilcox is an employee of Janssen Pharmaceuticals.

\section{Ethical Standards}

The authors assert that all procedures contributing to this work comply with the ethical standards of the relevant national and institutional committees on human experimentation and with the Helsinki Declaration of 1975, as revised in 2008.

\section{Supplementary materials and methods}

The supplementary materials referred to in this article can be found at http://dx.doi.org/10.1017/S2045796015000189

\section{References}

Altemus M, Sarvaiya N, Neill Epperson C (2014). Sex differences in anxiety and depression clinical perspectives. Frontiers in Neuroendocrinology 35, 320-330.

Andrade L, Caraveo-Anduaga JJ, Berglund P, Bijl RV, Dragomericka E, Kohn R, Keller MB, Kessler RC, Kawakami N, Kilic C, D, O, Ustun TB, Vicente B, Wittchen $H$ (2003). The epidemiology of major depressive episodes: results from the International Consortium of Psychiatric Epidemiology (ICPE) Surveys. International Journal of Methods in Psychiatric Research 12, 3-21.

Asselmann E, Wittchen HU, Lieb R, Hofler M,

Beesdo-Baum K (2015). Danger and loss events and the incidence of anxiety and depressive disorders: a prospective-longitudinal community study of adolescents and young adults. Psychological Medicine 45, 153-163.

Beesdo K, Pine DS, Lieb R, Wittchen HU (2010). Incidence and risk patterns of anxiety and depressive disorders and 
categorization of generalized anxiety disorder. Archives of General Psychiatry 67, 47-57.

Bernert S, Matschinger $\mathrm{H}$, Alonso J, Haro JM, Brugha TS, Angermeyer MC (2009). Is it always the same? Variability of depressive symptoms across six European countries. Psychiatry Research 168, 137-144.

Birnbaum HG, Kessler RC, Kelley D, Ben-Hamadi R, Joish VN, Greenberg PE (2010). Employer burden of mild, moderate, and severe major depressive disorder: mental health services utilization and costs, and work performance. Depression and Anxiety 27, 78-89.

Bittner A, Goodwin RD, Wittchen HU, Beesdo K, Hofler M, Lieb R (2004). What characteristics of primary anxiety disorders predict subsequent major depressive disorder? Journal of Clinical Psychiatry 65, 618-626, quiz 730.

Copeland WE, Shanahan L, Costello EJ, Angold A (2009). Childhood and adolescent psychiatric disorders as predictors of young adult disorders. Archives of General Psychiatry 66, 764-772.

Cuijpers P, Sijbrandij M, Koole S, Huibers M, Berking M, Andersson G (2014). Psychological treatment of generalized anxiety disorder: a meta-analysis. Clinical Psychology Review 34, 130-140.

Cummings CM, Caporino NE, Kendall PC (2014). Comorbidity of anxiety and depression in children and adolescents: 20 years after. Psychological Bulletin 140, 816-845.

de Graaf R, ten Have M, Tuithof M, van Dorsselaer S (2013). First-incidence of DSM-IV mood, anxiety and substance use disorders and its determinants: results from the Netherlands Mental Health Survey and Incidence Study-2. Journal of Affective Disorders 149, 100-107.

Fichter MM, Quadflieg N, Fischer UC, Kohlboeck G (2010). Twenty-five-year course and outcome in anxiety and depression in the Upper Bavarian Longitudinal Community Study. Acta Psychiatrica Scandinavica 122, 75-85.

Finlay-Jones R, Brown GW (1981). Types of stressful life event and the onset of anxiety and depressive disorders. Psychological Medicine 11, 803-815.

First M, Spitzer R, Gibbon M, Williams J (2002). Structured Clinical Interview for DSM-IV Axis I Disorders, Research Version, Non-patient Edition (SCID-I/NP). Biometrics

Research, New York State Psychiatric Institute: New York.

Flannery-Schroeder EC (2006). Reducing anxiety to prevent depression. American Journal of Preventive Medicine 31, S136-S142.

Garber J, Weersing VR (2010). Comorbidity of anxiety and depression in youth: implications for treatment and prevention. Clinical Psychology: a Publication of the Division of Clinical Psychology of the American Psychological Association 17, 293-306.

Goodwin R, Olfson M (2001). Treatment of panic attack and risk of major depressive disorder in the community. American Journal of Psychiatry 158, 1146-1148.

Goodwin RD, Gorman JM (2002). Psychopharmacologic treatment of generalized anxiety disorder and the risk of major depression. American Journal of Psychiatry 159, 1935-1937.

Hamdi NR, Iacono WG (2014). Lifetime prevalence and co-morbidity of externalizing disorders and depression in prospective assessment. Psychological Medicine 44, 315-324.
Harkness J, Pennell BE, Villar A, Gebler N, Aguilar-Gaxiola S, Bilgen I (2008). Translation procedures and translation assessment in the World Mental Health Survey Initiative. In The WHO World Mental Health Surveys: Global Perspectives on the Epidemiology of Mental Disorders (ed. RC Kessler and TB Üstün), pp. 91-113. Cambridge University Press: New York, NY.

Haro JM, Arbabzadeh-Bouchez S, Brugha TS, de Girolamo G, Guyer ME, Jin R, Lepine JP, Mazzi F, Reneses B, Vilagut G, Sampson NA, Kessler RC (2006). Concordance of the Composite International Diagnostic Interview Version 3.0 (CIDI 3.0) with standardized clinical assessments in the WHO World Mental Health surveys. International Journal of Methods in Psychiatric Research 15, 167-180.

Hayward C, Varady S, Albano AM, Thienemann M, Henderson L, Schatzberg AF (2000). Cognitive-behavioral group therapy for social phobia in female adolescents: results of a pilot study. Journal of the American Academy of Child and Adolescent Psychiatry 39, 721-726.

Heeringa S, Wells J, Hubbard F, Mneimneh Z, Chiu W, Sampson N (2008). Sample designs and sampling procedures. In The WHO World Mental Health Surveys: Global Perspectives on the Epidemiology of Mental Disorders (ed. RC Kessler and T Üstün), pp. 14-32. Cambridge University Press: New York.

Hofmann SG, Smits JA (2008). Cognitive-behavioral therapy for adult anxiety disorders: a meta-analysis of randomized placebo-controlled trials. Journal of Clinical Psychiatry 69, 621-632.

Jacobi F, Wittchen HU, Holting C, Hofler M, Pfister H, Muller N, Lieb R (2004). Prevalence, co-morbidity and correlates of mental disorders in the general population: results from the German Health Interview and Examination Survey (GHS). Psychological Medicine 34, 597-611.

Jakubovski E, Bloch MH (2014). Prognostic subgroups for citalopram response in the STAR*D trial. Journal of Clinical Psychiatry 75, 738-747.

Kelly JM, Jakubovski E, Bloch MH (2014). Prognostic subgroups for remission and response in the Coordinated Anxiety Learning and Management (CALM) trial. Journal of Clinical Psychiatry.

Kendler KS, Hettema JM, Butera F, Gardner CO, Prescott CA (2003). Life event dimensions of loss, humiliation, entrapment, and danger in the prediction of onsets of major depression and generalized anxiety. Archives of General Psychiatry 60, 789-796.

Kessler RC (1995). Epidemiology of psychiatric comorbidity. In Textbook in Psychiatric Epidemiology (ed. MT Tsuang and GEP Zahner), p. 18. John Wiley \& Sons, Inc: New York.

Kessler RC, Üstün TB (2004). The World Mental Health (WMH) Survey Initiative Version of the World Health Organization (WHO) Composite International Diagnostic Interview (CIDI). International Journal of Methods in Psychiatric Research 13, 93-121.

Kessler RC, Keller MB, Wittchen HU (2001). The epidemiology of generalized anxiety disorder. Psychiatric Clinics of North America 24, 19-39.

Kessler RC, Ormel J, Petukhova M, McLaughlin KA, Green JG, Russo LJ, Stein DJ, Zaslavsky AM, Aguilar-Gaxiola S, 
Alonso J, Andrade L, Benjet C, de Girolamo G, de Graaf R, Demyttenaere K, Fayyad J, Haro JM, Hu C, Karam A, Lee S, Lepine JP, Matchsinger H, Mihaescu-Pintia C, Posada-Villa J, Sagar R, Ustun TB (2011a). Development of lifetime comorbidity in the World Health Organization world mental health surveys. Archives of General Psychiatry 68, 90-100.

Kessler RC, Petukhova M, Zaslavsky AM (2011b). The role of latent internalizing and externalizing predispositions in accounting for the development of comorbidity among common mental disorders. Current Opinions in Psychiatry 24, 307-312.

Klein DN, Glenn CR, Kosty DB, Seeley JR, Rohde P, Lewinsohn PM (2013). Predictors of first lifetime onset of major depressive disorder in young adulthood. Journal of Abnormal Psychology 122, 1-6.

Knäuper B, Cannell CF, Schwarz N, Bruce ML, Kessler RC (1999). Improving accuracy of major depression age-of-onset reports in the US National Comorbidity Survey. International Journal of Methods in Psychiatric Research 8, 39-48.

Lamers F, van Oppen P, Comijs HC, Smit JH, Spinhoven P, van Balkom AJ, Nolen WA, Zitman FG, Beekman AT, Penninx BW (2011). Comorbidity patterns of anxiety and depressive disorders in a large cohort study: the Netherlands Study of Depression and Anxiety (NESDA). Journal of Clinical Psychiatry 72, 341-348.

Leach LS, Butterworth P, Olesen SC, Mackinnon A (2013). Relationship quality and levels of depression and anxiety in a large population-based survey. Social Psychiatry and Psychiatric Epidemiology 48, 417-425.

Leon AC, Olfson M, Portera L, Farber L, Sheehan DV (1997). Assessing psychiatric impairment in primary care with the Sheehan Disability Scale. International Journal of Psychiatry in Medicine 27, 93-105.

Li Y, Aggen S, Shi S, Gao J, Tao M, Zhang K, Wang X, Gao C, Yang L, Liu Y, Li K, Shi J, Wang G, Liu L, Zhang J, Du B, Jiang G, Shen J, Zhang Z, Liang W, Sun J, Hu J, Liu T, Miao G, Meng H, Hu C, Huang G, Li G, Ha B, Deng H, Mei Q, Zhong H, Gao S, Sang H, Zhang Y, Fang X, Yu F, Yang D, Chen Y, Hong X, Wu W, Chen G, Cai M, Song Y, Pan J, Dong J, Pan R, Zhang W, Shen Z, Liu Z, Gu D, Liu X, Zhang Q, Flint J, Kendler KS (2014). Subtypes of major depression: latent class analysis in depressed Han Chinese women. Psychological Medicine 44, 3275-3288.

Lin CH, Wang FC, Lin SC, Chen CC, Huang CJ (2014). A comparison of inpatients with anxious depression to those with nonanxious depression. Psychiatry Research 220, 855-860.

Mathew AR, Pettit JW, Lewinsohn PM, Seeley JR, Roberts RE (2011). Co-morbidity between major depressive disorder and anxiety disorders: shared etiology or direct causation? Psychological Medicine 41, 2023-2034.

McDowell RD, Ryan A, Bunting BP, O'Neill SM, Alonso J, Bruffaerts R, de Graaf R, Florescu S, Vilagut G, de Almeida JM, de Girolamo G, Haro JM, Hinkov $H$, Kovess-Masfety V, Matschinger H, Tomov T (2014). Mood and anxiety disorders across the adult lifespan: a European perspective. Psychological Medicine 44, 707-722.

McLaughlin TP, Khandker RK, Kruzikas DT, Tummala R (2006). Overlap of anxiety and depression in a managed care population: prevalence and association with resource utilization. Journal of Clinical Psychiatry 67, 1187-1193.

McLean PD, Woody S, Taylor S, Koch WJ (1998). Comorbid panic disorder and major depression: implications for cognitive-behavioral therapy. Journal of Consulting and Clinical Psychology 66, 240-247.

Merikangas KR, Jin R, He JP, Kessler RC, Lee S, Sampson NA, Viana MC, Andrade LH, Hu C, Karam EG, Ladea M, Medina-Mora ME, Ono Y, Posada-Villa J, Sagar R, Wells JE, Zarkov Z (2011). Prevalence and correlates of bipolar spectrum disorder in the world mental health survey initiative. Archives of General Psychiatry 68, 241-251.

Mineka S, Vrshek-Schallhorn S (2008). Comorbidity of unipolar depressive and anxiety disorders. In Handbook of Depression (ed. IH Gotlib and CL Hammen), pp. 84-102. Guilford Press: New York.

Moffitt TE, Caspi A, Harrington H, Milne BJ, Melchior M, Goldberg D, Poulton R (2007). Generalized anxiety disorder and depression: childhood risk factors in a birth cohort followed to age 32. Psychological Medicine 37, 441-452.

Moffitt TE, Caspi A, Taylor A, Kokaua J, Milne BJ, Polanczyk G, Poulton R (2010). How common are common mental disorders? Evidence that lifetime prevalence rates are doubled by prospective versus retrospective ascertainment. Psychological Medicine 40, 899-909.

Murphy JM, Olivier DC, Sobol AM, Monson RR, Leighton AH (1986). Diagnosis and outcome: depression and anxiety in a general population. Psychological Medicine 16, 117-126.

Ormel J, VonKorff M, Ustun TB, Pini S, Korten A, Oldehinkel T (1994). Common mental disorders and disability across cultures. Results from the WHO Collaborative Study on Psychological Problems in General Health Care. Journal of the American Medical Association 272, 1741-1748.

Ormel J, Petukhova M, Chatterji S, Aguilar-Gaxiola S, Alonso J, Angermeyer MC, Bromet EJ, Burger $\mathrm{H}$, Demyttenaere K, de Girolamo G, Haro JM, Hwang I, Karam E, Kawakami N, Lepine JP, Medina-Mora ME, Posada-Villa J, Sampson N, Scott K, Ustun TB, Von Korff M, Williams DR, Zhang M, Kessler RC (2008).

Disability and treatment of specific mental and physical disorders across the world. British Journal of Psychiatry 192, 368-375.

Parker G, Brotchie H (2010). Gender differences in depression. International Review of Psychiatry 22, 429-436.

Pennell B, Mneimneh Z, Bowers A, Chardoul S, Wells J, Viana M, Dinkelmann K, Gebler N, Florescu S, He Y, Huang Y, Tomov T, Vilagut G (2008). Implementation of the World Mental Health Surveys. In The WHO World Mental Health Surveys: Global Perspectives on the Epidemiology of Mental Disorders (ed. R Kessler and T Ustun), pp. 33-57. Cambridge University Press: Cambridge, UK.

Rapee RM, Lyneham HJ, Hudson JL, Kangas M, Wuthrich VM, Schniering CA (2013). Effect of comorbidity on treatment of anxious children and adolescents: results from a large, combined sample. Journal of the American Academy of Child and Adolescent Psychiatry 52, 47-56.

Research Triangle Institute (2002). SUDAAN: Professional Software for Survey Data Analysis [computer program]. Research Triangle Institute: Research Triangle Park, NC. 
Roy-Byrne PP, Stang P, Wittchen HU, Ustun B, Walters EE, Kessler RC (2000). Lifetime panic-depression comorbidity in the National Comorbidity Survey. Association with symptoms, impairment, course and help-seeking. British Journal of Psychiatry 176, 229-235.

Saveanu R, Etkin A, Duchemin AM, Goldstein-Piekarski A, Gyurak A, Debattista C, Schatzberg AF, Sood S, Day CV, Palmer DM, Rekshan WR, Gordon E, Rush AJ, Williams LM (2014). The International Study to Predict Optimized Treatment in Depression (iSPOT-D): outcomes from the acute phase of antidepressant treatment. Journal of Psychiatric Research.

Schrier AC, de Wit MA, Rijmen F, Tuinebreijer WC, Verhoeff AP, Kupka RW, Dekker J, Beekman AT (2010). Similarity in depressive symptom profile in a population-based study of migrants in the Netherlands. Social Psychiatry and Psychiatric Epidemiology 45, 941-951.

Scott KM, Wells JE, Angermeyer M, Brugha TS, Bromet E, Demyttenaere K, de Girolamo G, Gureje O, Haro JM, Jin R, Karam AN, Kovess V, Lara C, Levinson D, Ormel J, Posada-Villa J, Sampson N, Takeshima T, Zhang M, Kessler RC (2010). Gender and the relationship between marital status and first onset of mood, anxiety and substance use disorders. Psychological Medicine 40, 1495-1505.

Shippee ND, Rosen BH, Angstman KB, Fuentes ME, DeJesus RS, Bruce SM, Williams MD (2014). Baseline screening tools as indicators for symptom outcomes and health services utilization in a collaborative care model for depression in primary care: a practice-based observational study. General Hospital Psychiatry 36, 563-569.

Simon GE, Goldberg DP, Von Korff M, Ustun TB (2002). Understanding cross-national differences in depression prevalence. Psychological Medicine 32, 585-594.

Stiles-Shields C, Kwasny MJ, Cai X, Mohr DC (2014). Comorbid anxiety as a differential treatment predictor for telephone versus face-to-face administered cognitive behavioral therapy for depression. Depression and Anxiety 31, 934-940.

Takayanagi Y, Spira AP, Roth KB, Gallo JJ, Eaton WW, Mojtabai R (2014). Accuracy of reports of lifetime mental and physical disorders: results from the Baltimore Epidemiological Catchment Area study. JAMA Psychiatry 71, 273-280.

van Loo HM, de Jonge P, Romeijn JW, Kessler RC, Schoevers RA (2012). Data-driven subtypes of major depressive disorder: a systematic review. BMC Medicine 10, 156.

Vos T, Flaxman AD, Naghavi M, Lozano R, Michaud C, Ezzati M, Shibuya K, Salomon JA, Abdalla S, Aboyans V et al. (2012). Years lived with disability (YLDs) for 1160 sequelae of 289 diseases and injuries 1990-2010: a systematic analysis for the Global Burden of Disease Study 2010. Lancet 380, 2163-2196.

Wang PS, Aguilar-Gaxiola S, Alonso J, Angermeyer MC, Borges G, Bromet EJ, Bruffaerts R, de Girolamo G, de Graaf R, Gureje O, Haro JM, Karam EG, Kessler RC, Kovess V, Lane MC, Lee S, Levinson D, Ono $Y$, Petukhova M, Posada-Villa J, Seedat S, Wells JE (2007). Use of mental health services for anxiety, mood, and substance disorders in 17 countries in the WHO world mental health surveys. Lancet 370, 841-850.

Wolter KM (1985). Introduction to Variance Estimation. Springer-Verlag: New York, NY.

Woody S, McLean PD, Taylor S, Koch WJ (1999). Treatment of major depression in the context of panic disorder. Journal of Affective Disorders 53, 163-174.

World Bank (2009). Data \& Statistics, Country Groups by Income. From http://go.worldbank.org/D7SN0B8YU0.

Wu Z, Fang Y (2014). Comorbidity of depressive and anxiety disorders: challenges in diagnosis and assessment. Shanghai Arch Psychiatry 26, 227-231. 